\title{
REVIEW
}

\section{Redifferentiation of radioiodine-refractory thyroid cancers}

\author{
Camille Buffet ${ }^{1}$, Johanna Wassermann ${ }^{2}$, Fabio Hecht ${ }^{3}$, Laurence Leenhardt ${ }^{1}$, Corinne Dupuy 4,5 , Lionel Groussin ${ }^{6,7,8}$ \\ and Charlotte Lussey-Lepoutre ${ }^{9,10}$
}

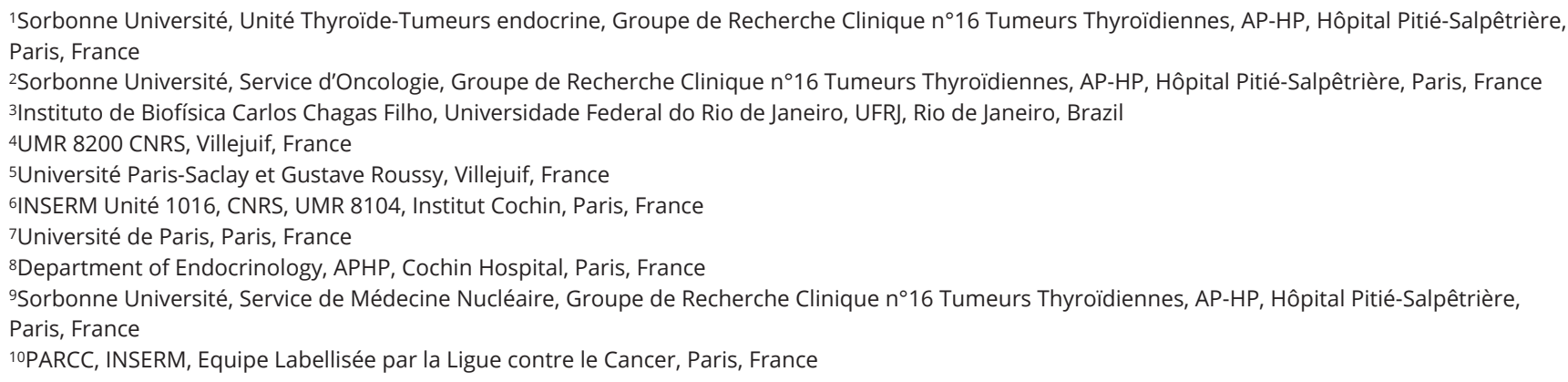

Correspondence should be addressed to C Buffet or C Lussey-Lepoutre: camille.buffet@aphp.fr or charlotte.lussey@inserm.fr

\begin{abstract}
The management of radioiodine refractory thyroid cancers (RAIR TC) is challenging for the clinician. Tyrosine kinase inhibitors classically prescribed in this setting can fail due to primary or acquired resistance or the necessity of drug withdrawal because of serious or moderate but chronic and deleterious adverse effects. Thus, the concept of redifferentiation strategy, which involves treating patients with one or more drugs capable of restoring radioiodine sensitivity for RAIR TC, has emerged. The area of redifferentiation strategy leads to the creation of new definitions of RAIR TC including persistent non radioiodine-avid patients and 'true' RAIR TC patients. The latter group presents a restored or increased radioiodine uptake in metastatic lesions but with no radiological response on conventional imaging, that is, progression of a metastatic disease, thus proving that they are 'truly' resistant to the radiation delivered by radioiodine. Unlike these patients, metastatic TC patients with restored radioiodine uptake offer the hope of prolonged remission or even cure of the disease as for radioiodine-avid metastatic TC. Here, we review the different redifferentiation strategies based on the underlying molecular mechanism leading to the sodium iodide symporter (NIS) and radioiodine uptake reinduction, that is, by modulating signaling pathways, NIS transcription, NIS trafficking to the plasma membrane, NIS post-transcriptional regulation, by gene therapy and other potential strategies. We discuss clinical trials and promising preclinical data of potential future targets.
\end{abstract}

\author{
Key Words \\ - NIS \\ - radioiodine refractory \\ thyroid cancers \\ - redifferentiation \\ - MAPK inhibition \\ - NIS trafficking \\ - epigenetic regulation
}

C 2020 Society for Endocrinology Published by Bioscientifica Ltd. Printed in Great Britain
Endocrine-Related Cancer (2020) 27, R113-R132 


\section{Introduction}

Although the majority of patients with differentiated thyroid cancers (DTC) could be successfully managed by surgery and radioiodine administration, for which the indication is decided according to published guidelines (Haugen et al. 2016, Ahuja et al. 2019, Luster et al. 2019), the evolution of a minority of these DTC will be less favourable and will require personalized management. Distant metastases encountered in less than $10 \%$ of DTC (https://seer.cancer.gov/statfacts/html/thyro.html) can lead to serious complications and even decrease the survival of patients (Wassermann et al. 2016). Radioiodine therapy is the cornerstone of the treatment of distant metastases from DTC. This therapy is based on the expression at the plasma membrane of normal and tumoral thyroid epithelial cells of a symporter, the sodium iodide symporter (NIS), that transports two sodium ions and one iodide ion into the cytosol. Iodide is then handled by an iodine-metabolizing machinery that concentrates iodine into the thyroid cells which has probably a major impact on radioiodine efficacy. One-third of metastatic DTC patients will be in remission after one or more radioiodine sessions (Durante et al. 2006). The others are or will become radioiodine refractory (RAIR), which is correlated with high tumor burden (multiple and macrometastases) along with a less differentiated tumor state and worse prognosis (Wassermann et al. 2016, Deandreis et al. 2017). Dedifferentiation is related to a decrease in or a loss of NIS expression, and/or targeting to the plasma membrane where NIS is fully effective, which results in the loss of iodine uptake in thyroid cells (Fig. 1). Other histological types are less or not at all sensitive to radioiodine such as poorly DTC (PDTC) or anaplastic thyroid cancer (ATC) as these tumours have also lost the expression of thyroid specific genes, particularly those encoding for the iodinemetabolizing machinery during the dedifferentiation process. Therapeutic strategies for RAIR thyroid cancers include the implementation of local therapy (surgery, external radiotherapy, interventional radiology approach) whenever possible and, in the case of diffuse significant progression of distant metastatic disease systemic therapy, mainly tyrosine kinase inhibitors (TKI). However, TKI raise various issues such as primary and acquired resistance with tumor escape on the one hand and on the other hand serious and/or moderate but chronic and deleterious adverse effects, especially for antiangiogenic TKI. Thus, the concept of redifferentiation strategy has emerged with a view to finding one or more drugs capable of restoring radioiodine sensitivity for RAIR thyroid cancers (Fig. 1).
One of the challenges of this redifferentiation strategy is to find a treatment protocol involving the short-term use of systemic therapy so that, even if side effects occur, they only have to be tolerated temporarily and frequently vanish with the discontinuation of re-differentiation treatment. Numerous compounds have been tested for several years with inconsistent results. A renewed interest for this strategy came from the publication of a pilot trial with a series of 24 patients showing promising results obtained with a pharmacological MEK inhibitor

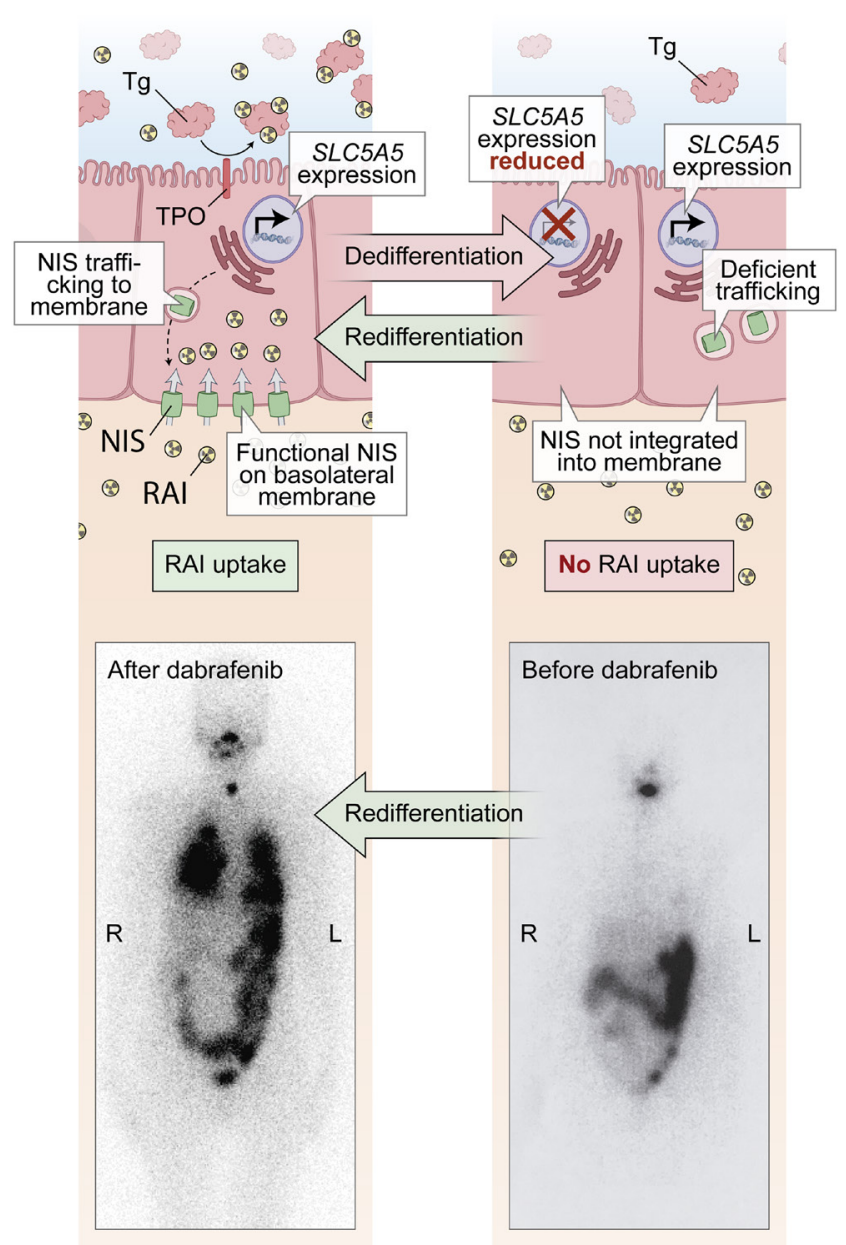

\section{Figure 1}

Differentiation and redifferentiation of thyroid cancer schematic. The left panel illustrates a (re-)differentiated state where the sodium iodide symporter (NIS) is normally expressed and localized at the plasma membrane, allowing radioactive iodine (RAI) to be uptaken by tumoral cells. The right panel illustrates a dedifferentiated state where the expression of the SLC5A5 gene, encoding for the NIS, is reduced and/or not correctly targeted to the plasma membrane and consequently with no RAl uptake. The bottom panels illustrate the case of a patient with metastatic RAI refractory papillary thyroid cancer treated for 8 weeks with dabrafenib. The post-therapeutic WBS after dabrafenib demonstrates a clear restoration of RAI uptake in the metastatic sites (lung and neck lymphadenopathy). (c) 2020 Society for Endocrinology Published by Bioscientifica Ltd. Printed in Great Britain 
prescribed for 4 weeks (Ho et al. 2013), which was in line with the pre-clinical mouse model validating this strategy (Chakravarty et al. 2011).

Here, we discuss the different redifferentiation strategies based on the underlying molecular mechanism leading to NIS and radioiodine uptake reinduction, that is, by modulating signaling pathways, NIS transcription, NIS trafficking to the plasma membrane, NIS posttranscriptional regulation, by gene therapy and other potential strategies. From a pre-clinical point of view, our review focuses on studies with data obtained from at least one cell line of authenticated thyroid cancer origin, as some cell lines tested in several studies were subsequently found to be of non-thyroid origin (Schweppe et al. 2008, Landa et al. 2019). Finally, promising results of clinical trials on redifferentiation strategies are outlined.

\section{Modulation of signaling pathways}

\section{Modulation of the MAPK pathway: preclinical and clinical evidence}

Several publications demonstrate that MAPK pathway activation is associated with dedifferentiation and in particular NIS repression (Fig. 2). The comprehensive characterization of 496 papillary thyroid cancers (PTC) published in 2014 by the The Cancer Genome Atlas (TCGA) Research Network highlighted that BRAFV600E_ mutated PTC, which had the strongest activation of the MAPK pathway, showed the most dedifferentiated state, that is, low expression of some thyroid differentiation genes such as the SCLC5A5 gene encoding for the NIS, thyroglobulin (Tg) or thyroperoxydase (TPO) (Cancer Genome Atlas Research 2014).

Several in vitro studies have demonstrated an increase in NIS expression and/or radioiodine uptake in human thyroid cancer-derived cell lines with various genetic backgrounds or patient-derived tumor tissue of ATC and PDTC with different MAPK pathway inhibitors namely BRAFV600E inhibitors such as vemurafenib (Cheng et al. 2016, Zhang \& Chen 2018) or dabrafenib (Fu et al. 2019), multityrosine kinase inhibitor such as sorafenib (Ruan et al. 2015, Wachter et al. 2018a) or cabozantinib (Ruan et al. 2015) and MEK inhibitors such as selumetinib (Wachter et al. 2018a,b, Fu et al. 2019), PD98059 (Vadysirisack et al. 2007, Hou et al. 2010, Zhang \& Chen 2018) or refametinib (Hou et al. 2010).

The first clinical phase II study testing a pharmacological inhibitor of the MAPK pathway reported the effect of the multityrosine kinase inhibitor sorafenib in 31 patients (Hoftijzer et al. 2009). This study was based on in vitro data demonstrating that another multityrosine kinase inhibitor namely sunitinib was able to induce NIS expression in PTC cell lines harboring RET/PTC1 rearrangement through inhibition of the MEK/ERK and SAPK/JNK pathway (Fenton et al. 2010) and that sunitinib increased iodine uptake in normal rat thyroid cells (Salem et al. 2008). Of the 20 patients evaluable for redifferentiation, after 26 weeks of treatment with sorafenib, only one restored a faint uptake of radioiodine in an occipital skeletal metastasis on the diagnostic whole body scan (WBS) performed, which was not confirmed on the therapeutic WBS performed after the administration of $200 \mathrm{mCi}$ (Hoftijzer et al. 2009). A renewed interest for redifferentiation strategy with MAPK pathway pharmacological inhibitors came from the publication

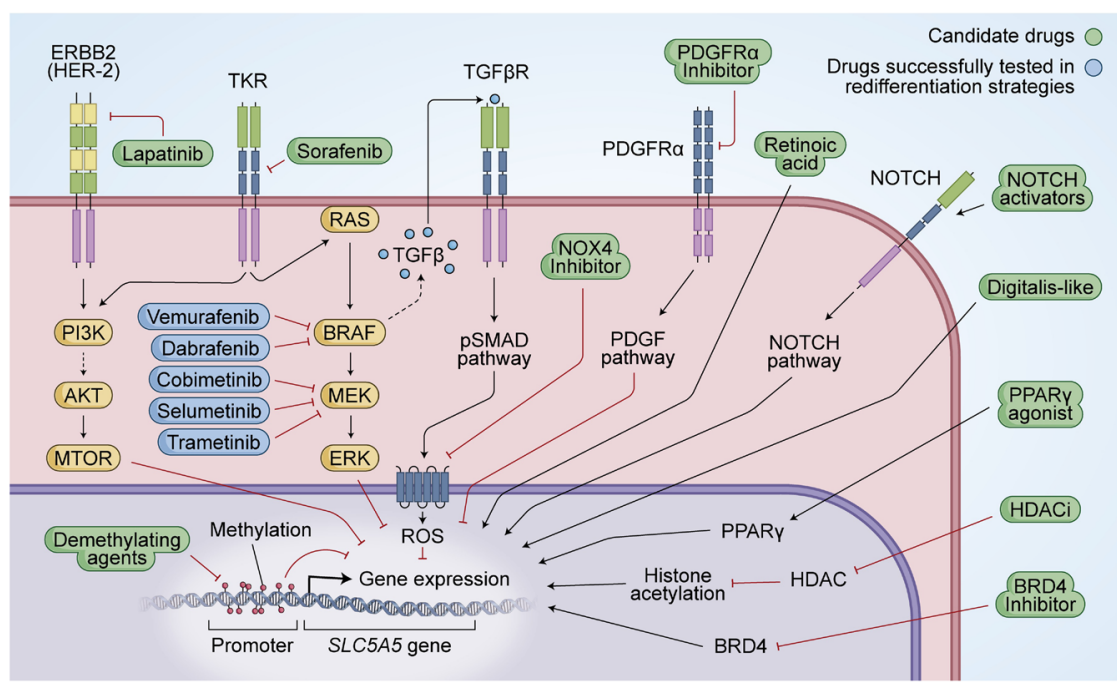

\section{Figure 2}

Molecular mechanism controlling NIS expression and current or future actionable targets. https://erc.bioscientifica.com https://doi.org/10.1530/ERC-19-0491 (c) 2020 Society for Endocrinology Published by Bioscientifica Ltd. Printed in Great Britain 
by the James Fagin laboratory (Memorial Sloan-Kettering Cancer Center, MSKCC) (Chakravarty et al. 2011). His team developed an ingenious mouse model expressing the BRAFV600E oncogene specifically in the thyrocytes and with the ability to switch the expression of BRAFV600E on and off with the administration or withdrawal of doxycycline (Chakravarty et al. 2011). Switching on $\mathrm{BRAF}^{\mathrm{V} 600 \mathrm{E}}$ expression induced thyroid cancers in mice that recapitulate most human BRAFV600E-tumor characteristics and was associated with a virtual abolition of thyroidspecific gene expression along with radioiodine uptake. Switching off BRAFV600E restored not only thyroid follicular architecture but also thyroid-specific gene expression and radioiodine incorporation. Pharmacological inhibitors of MEK, that is, selumetinib or BRAFV600E inhibitor, that is, dabrafenib for 2 weeks, partially restored thyroid-specific gene expression and radioiodine uptake. Following this preclinical in vivo model, Ho et al. from the MSKCC performed a clinical study in 24 patients with PTC or follicular thyroid cancer (FTC) or poorly DTC, confirming the ability of selumetinib to restore radioiodine in tumors previously shown to be radioiodine resistant (Ho et al. 2013). In this study, patients were treated with selumetinib for 4 weeks and then submitted to an 124-iodine PET-CT under thyrotropin stimulation to estimate the activity of 131-iodine required to deliver an arbitrary dose of 2000 cGy and above to the metastatic lesions. If it appeared that at least one lesion could be treated by an activity of less than $300 \mathrm{mCi}$, the patient was then treated with a personalized therapeutic dose of 131-iodine. Out of the 20 patients evaluable, selumetinib increased radioiodine uptake in 12 . Of these 12 patients, eight reached the dosimetry threshold for radioiodine therapy, including all five patients with NRAS mutation but only one out of nine patients with BRAFV600E mutation. Of the eight patients treated with radioiodine, seven had a confirmed radiological partial response according to the RECIST 1.1 criteria, 6 months after selumetinib withdrawal and radioiodine therapy. The authors attributed their good results in a large part to the dosimetric approach enabled by the 124-iodine PET-CT evaluation of the patients. This publication has opened the field of successful redifferentiation strategy with MAPK inhibitors (Table 1).

To confirm the data of the pilot study conducted by Ho et al., a multicenter UK single arm phase II trial (SEL-I-METRY) has opened (Brown et al. 2019). Patients with locally advanced or metastatic RAIR DTC or PDTC treated for 4 weeks with selumetinib are evaluated by 123-iodine SPECT/CT under recombinant human TSH to select patients showing significant increase in 123-iodine uptake and who will subsequently be treated with a fixed activity of $150 \mathrm{mCi}$ of 131-radioiodine.

Despite these encouraging preliminary results on RAIR DTC patients, the results of the ASTRA phase III study (NCT01843062) evaluating MEK inhibitors as an adjuvant therapy in non-proved RAIR DTC were disappointing. This trial included patients with DTC at high risk of recurrence after total thyroidectomy (i.e. pT $>4 \mathrm{~cm}, \mathrm{pT} 4, \mathrm{~N} 1$ with $\geq 5$ lymph nodes or with at least 1 lymph node $\geq 1 \mathrm{~cm}$ ). Patients were randomized to receive placebo or selumetinib for 4 weeks prior radioiodine ablation to assess the effect of selumetinib on the complete remission rate at 18 months. The addition of selumetinib to radioiodine did not improve the complete remission rate $(40 \%$ vs $38.5 \%$ in the placebo group) in this patient population, in any subgroup of patients, even when genotype was taken into account. However, the placebo group established a $38.5 \%$ complete remission rate with standard radioiodine alone in highrisk patients, suggesting the need for improved therapeutic approaches. Subgroup analyses of this trial suggest that treatment compliance and tailoring the targeted therapy approach to the oncogenic driver mutation, especially the absence of a BRAF mutation, may be critical design elements to consider for future trials (unpublished data from J. Fagin's team).

Owing to the relatively poor response of BRAFmutated thyroid cancers in the study published by Ho et al., others have evaluated the capacity of the selective BRAFV600E inhibitor dabrafenib to specifically redifferentiate BRAFV600E (Rothenberg et al. 2015). Out of the ten patients included with a RAIR BRAF-mutated PTC, defined as the absence of radioiodine uptake on a first WBS (diagnostic or therapeutic dose), 6 weeks of dabrafenib restored radioiodine uptake on a diagnostic WBS in six of them. Those six patients were then treated with $150 \mathrm{mCi}$ 131-iodine with a therapeutic WBS confirming the data obtained with the diagnostic scan. Two patients showed partial response and four stable disease on standard radiological imaging obtained 3 months after radioiodine therapy and discontinuation of dabrafenib, while out of the four patients without restoration of radioiodine uptake, one had progressive disease and three stable disease. These results should be put into perspectives considering that, at study entry, five patients out of ten had progression per RECIST v1.1 within the14 months prior to enrolment. Ho and his team published another pilot trial (Dunn et al. 2019) evaluating vemurafenib in 12 patients with a BRAF mutated-PTC or PDTC, with a methodology similar to their first study (Ho et al. 2013). Out of the ten patients evaluable, 
Table 1 Published trials or clinical cases of redifferentiating strategy with MAPK inhibitors.

\begin{tabular}{|c|c|c|}
\hline & TKI & \\
\hline Reference & Duration of treatment before RAI & Patients $(n)$ \\
\hline Ho et al. (2013) & $\begin{array}{l}\text { Selumetinib (MEKi) } \\
4 \text { weeks }\end{array}$ & $\begin{array}{l}24 \\
20 \text { evaluabl }\end{array}$ \\
\hline
\end{tabular}

Rothenberg et al. (2015)

Huillard et al. (2017)

Dabrafenib (BRAF $\left.{ }^{\mathrm{V} 600} \mathrm{i}\right)$

6 weeks

Vemurafenib, and then dabrafenib

Several months, without withdrawal

\section{Main results}

- RAl uptake: $60 \%$ (12/20) of increase or induction

$40 \%(8 / 20)$ retreated with RAI : 5/5 NRAS - 1/9 BRAF - 1/3 RET/PTC - 1/3 WT (Best responders: RAS mutated patients) At 6 months: 5 PR and 3 SD

- $60 \%(6 / 10)$ retreated with RAI

- At 3 months: 2 PR and 4 SD

- Increase in Tg (redifferentiation effect) while on TKI

- Diagnosis of an unsuspected pulmonary miliary on therapeutic WBS

Loss of the redifferentiation effect after short and transitory interruption of the TKI

Jaber et al. (2018)

Dabrafenib \pm trametinib

Vemurafenib (BRAF $\left.{ }^{\mathrm{V} 600 \mathrm{E}} \mathrm{i}\right)$

Trametinib (MEKi)

Investigational MEKi

Median duration of treatment: 14 months

Dunn et al. (2019)

Vemurafenib

4 weeks

13

12

BRAFV600E

10 evaluable

Trametinib \pm dabrafenib

Vemurafenib + cobimetinib (MEKi)

4 weeks

RAl uptake: $69 \%$ (9/13) of increase or induction (3/3 RAS - 5/9 BRAF - 1/1 WT; Best responders: RAS mutated patients) Increase in Tg or Tg Ab levels in 6 out of 9 responders while on TKI

- RAl uptake: $60 \%(6 / 10)$ of increase or induction

$40 \%(4 / 10)$ retreated with RAI

Iravani et al. (2019)

Leboulleux et al. (2019)

Dabrafenib + trametinib

8 weeks
6

- At 6 months: 2 PR and 2 SD

- $67 \%(4 / 6)$ retreated with RAI (1/3 NRAS

- 3/3 BRAF; Best responders: BRAF mutated patients)

- At 3 months: 3 PR - 1 SD

$1 \quad-$ Clinical hyperthyroidism and increase BRAFK601E in FT4 and FT3 $(6.6$ and 4.4 N) 8 weeks later

- Histological redifferentiation documented

- No therapeutic RAI because of unresectable primary thyroid tumor

BRAFV600E i: BRAFV600E inhibitor; MEKi: MEK inhibitor; PR: partial response; RAl: radioiodine; SD: stable disease; Tg Ab: thyroglobuline antibody; Tg: thyroglobuline.

four reached the dosimetry threshold on the 124-iodine PET scan and were retreated with a therapeutic dose of iodine 131. Of those four patients, radiological assessment revealed partial response $(n=2)$ and stable disease $(n=2)$ 6 months after radioiodine therapy. Interestingly, the serum Tg value among 124-iodine responders was significantly higher than in non-responders. This suggests that cancers with better differentiation at baseline (high serum $\mathrm{Tg}$ ) have a better chance to respond favourably to the redifferentiation strategy. Molecular tumor biopsy analysis performed before and under vemurafenib revealed that, to some extent, the degree of iodine avidity restoration is linked to the degree of MAPK pathway output inhibition and the induction of thyroid-specific gene expression.

The retrospective analysis of patients with RAIR DTC (PTC, FTC or PDTC) treated with MAPK inhibitors (BRAFV600E and/or MEK inhibitors), for a mean of 14 months, also confirmed the data described previously (Jaber et al. 2018, Iravani et al. 2019). In the first study (Jaber et al. 2018), 9 out of 13 patients were treated with a therapeutic dose of 150-250 mCi of radioiodine based on meaningful uptake of radioiodine on a diagnostic WBS except for one. All nine patients had durable disease control. As previously reported, RAS-mutated tumors were the best responders compared to BRAF-mutated ones. In the second study (Iravani et al. 2019), out of six patients treated with MEK inhibitor (NRAS mutated) or BRAF and MEK inhibitors (BRAF mutated) for 4 weeks, four were considered suitable for radioiodine therapy based on the result of I124 PET/CT, with I131 post-therapeutic WBS confirming the restoration of radioiodine uptake. In this study, all BRAF-mutated patients responded to the redifferentiation strategy, while only one NRASmutated patient out of three did. Of these four patients, 
three achieved a partial imaging response (while progressing or stable at study entry) and one stable disease (while progressing at study entry) after a median follow-up of 16.6 months. Additional case reports demonstrated the potential redifferentiating effect of pharmacological MAPK inhibition in thyroid cancers (Huillard et al. 2017, Leboulleux et al. 2019). In one of these case reports clinical hyperthyroidism developed, with free triiodothyronine and free thyroxine levels increasing to 6.6 and 4.4 times their upper reference limit, as ultimate evidence of efficient redifferentiation (Leboulleux et al. 2019). In the study of Iravani et al., 4 weeks of thyroid hormone withdrawal increased TSH to only $25.9 \mathrm{mUI} / \mathrm{L}$ in one patient submitted to a redifferentiation strategy with MEK and BRAF inhibitors, suggesting the redifferentiation of functional thyroid cancer cells.

In the context of a redifferentiation strategy, some patients in the studies by Huillard et al. (2017) and Dunn et al. (2019) demonstrated a rise in thyroglobulin, which may indicate the success of redifferentiation rather than disease progression. Interestingly, Huillard et al. demonstrated that a BRAFV600E inhibitor administered in a RAIR-PTC patient revealed unsuspected pulmonary miliary metastases on the therapeutic WBS performed. Finally, this case report also illustrated that the redifferentiation effect is transitory and disappears after a short period of discontinuation of the redifferentiation drug, highlighting the importance of radioiodine administration while the patient is under treatment.

However, in all these studies, it is difficult to distinguish between tumor response resulting from a cytotoxic effect of the pharmacological inhibitor and a restoration of radioiodine uptake. Selecting patients with mixed response, that is, patients with lesions showing new or enhanced radioiodine uptake and lesions without any uptake, could create the opportunity to distinguish between both effects (Huillard et al. 2015).

Future prospects to improve tumor redifferentiation, especially BRAFV600E-mutated thyroid cancers, through MAPK inhibition, might come from compounds able to profoundly inhibit the MAPK pathway, such as CKI a MEK inhibitor that functions as a dominant-negative inhibitor of RAF which reduces the feedback reactivation of ERK signaling. James Fagin's laboratory published data, in vitro, in rat thyroid cells expressing BRAFV600E and, in vivo, in a mouse model with BRAFV600E-induced thyroid cancer demonstrates that a small increase in ERK inhibition translates into a markedly increased expression of thyroid differentiation genes and increased iodide accumulation in cancer (Nagarajah et al. 2016).
A high-throughput NIS enhancer screening platform also enabled the identification of a new tyrosine kinase inhibitor which increased NIS promoter activity along with the expression of NIS and other thyroid specific proteins (Tg, TPO, TSH-R, Pax 8 and TTF-1) in a BRAFV600E_ mutated thyroid cancer cell line. Moreover this compound, which decreased the level of phosphorylated ERK, that is, the activation of the MAPK pathway, increased 125I uptake in the same cell line and in vivo in xenograft mice models (Oh et al. 2018). The combination of BRAFV600E and MEK inhibition may be a promising strategy, as the combination synergistically increased radioiodine uptake in human BRAF-mutated thyroid cancer cell lines possibly through inhibition of the rebound of ERK1/2 activation observed with only one drug (Zhang \& Chen 2018). An ongoing clinical trial performed by the French RAIR thyroid cancer TUTHYREF network is testing the association of MEK (Trametinib) alone (for RAS mutated tumors) or in combination with BRAFV600E (Dabrafenib) inhibitors (for BRAFV600E mutated tumors) followed by radioiodine therapy for the treatment of RAIR metastatic DTC (NCT 03244956).

Another strategy for BRAFV600E-mutated thyroid cancers would be to combine inhibitors of the human EGF receptor (Her) belonging to the EGF receptor family with MAPK inhibitors. In thyroid cancer cells harboring BRAFV600E mutation, inhibition of the MAPK pathway by pharmacological inhibitors were transient due to the release, by a RAF or MEK inhibitor, of a transcriptional repressor from the HER3 promoter and consequently induced HER3 gene overexpression (Montero-Conde et al. 2013). An autocrine secretion by thyroid cancer cells of a ligand able to bind to and activate by dimerization the tyrosine kinase receptors HER2/HER3 resulted in the reactivation of the MAPK and PI3K pathway. The Her kinase inhibitor lapatinib prevented MAPK rebound and overcame BRAF-mutated thyroid cancer cell resistance to MAPK inhibitors (Montero-Conde et al. 2013). In line with these data, Cheng et al. (2017) demonstrated in vitro in BRAFV600E-mutated human thyroid cancer derived cell lines that the combination of lapatinib with dabrafenib or selumetinib increased radioiodine uptake. A clinical trial (NCT 02456701), performed at the MSKCC and which tests the ability of vemurafenib combined with an anti HER3 MAB to restore iodine incorporation in BRAF mutant RAIR thyroid cancer patients, is ongoing.

Iodide oxidation and tyrosine organification are not restored by MAPK blockade. As PI3K inhibition seems to prolong radioiodine retention in thyroid cells (Lakshmanan et al. 2015), the combination of MAPK and (c) 2020 Society for Endocrinology Published by Bioscientifica Ltd. Printed in Great Britain 
PI3K inhibitors may be an interesting strategy, but with the disadvantage of potential synergistic side effects.

The potential of combining MAPK inhibitors with HDAC inhibitors is developed in the 'HDAC inhibitors' section of this review.

Concerning undifferentiated thyroid cancers, namely ATC, hope for successful redifferentiation comes from a mouse model of lethally aggressive thyroid cancer, harboring BRAFV600E and PIK3CA ${ }^{\mathrm{H} 1047 \mathrm{R}}$ mutations, demonstrating that MEK inhibition for only 10 days could increase radioiodine uptake, which could then translate into a stable and profound reduction in tumor burden (ElMokh et al. 2019).

\section{Modulation of other pathways: preclinical evidence}

\section{The PI3K pathway}

In a non-tumoral context, a central role for PI3K in the repression of NIS gene transcription by IGF1 has been demonstrated in the FRTL-5 rat thyroid cell line (Garcia \& Santisteban 2002). Paradoxically, Quercetin, a compound with PI3K inhibitory properties, has been shown to reduce NIS mRNA levels in FRTL-5 cells (Giuliani et al. 2008).

However, other publications have shown that PI3K pathway inhibition has the potential to restore radioiodine sensitivity of RAIR DTC (Fig. 2).

Song et al. (2018) demonstrated in vitro in thyroid cancer cell lines that a mutant RasGRP3 (Ras guanine nucleotide-releasing protein 3), which was frequently found in metastases of RAIR DTC, decreased iodine uptake ability besides promoting cell proliferation, migration and invasiveness. This was associated with PI3K pathway activation and the addition of the PI3K pathway pharmacological inhibitor LY294002 restored radioiodine uptake of the cells at their basal level, that is, without overexpression of RasGRP3 mutant. LY294002 also increased radioiodine uptake in human thyroid cancer cells expressing RET/PTC1 and engineered to constitutively express NIS (Kogai et al. 2008) and in the non-cancerous PCCL3 rat thyroid cells (de Souza et al. 2010) mainly through NIS upregulation (Liu et al. 2012).

Interestingly, pharmacological Akt inhibition increased radioiodine uptake, despite a decrease in NIS protein levels, in PCCL3 rat thyroid cells with doxycycline induced expression of constitutively active MEK. Indeed, this Akt1/2 inhibitor acted on iodine uptake through a decreased iodide efflux and a higher iodide affinity, enhancing the NIS-mediated iodide transport rate (Liu et al. 2012). The same research team further demonstrated that, among different pharmacological inhibitors targeting Akt, MEK, PI3K, Hsp90 or BRAFV600E tested in PCCL3 rat thyroid cells conditionally expressing RET/PTC3 or BRAFV600E, the PI3K inhibitor GDC-0941 outperformed other inhibitors in radioiodine increase (Lakshmanan et al. 2015). Surprisingly, the greatest effect was observed in BRAFV600E expressing thyroid cells, where MEK is the canonical downstream of BRAFV600E. Again, a decrease in iodide efflux was the main mechanism of action of this PI3K inhibitor which had limited effect on NIS protein levels. Of note, Lakshmanan et al. (2015) demonstrated that TGF $\beta$, present in the thyroid tumor microenvironment, reduces the extent of increase in radioiodine uptake induced by the pharmacological inhibitors tested. They also showed that Apigenin, a plantderived flavonoid, associated with GDC-0941 provided the highest radioiodine uptake level in both BRAFV600E and RET/PTC3 expressing PCCL3 cells, corroborating previous data obtained with an Akt pharmacological inhibitor in the same cells and in a mouse thyroid tumor model (Lakshmanan et al. 2014).

Another PI3K inhibitor, rapamycin, was found to induce NIS protein levels along with radioiodine uptake in BRAFV600E and RET/PTC1 PTC derived cell lines (but not in a FTC derived cell line), possibly through a transcriptional effect dependent on the transcription factor TTF1 (Plantinga et al. 2014). Rapamycin and its synthetic analog everolimus led to controversial results in a non-tumoral thyroid in vitro model (de Souza et al. 2010, Liu et al. 2012).

\section{Other pathways}

\section{The NOTCH signaling pathway}

Notch genes encode receptors for a signaling pathway that controls cell fate by regulating cell proliferation and differentiation, especially in oncogenic contexts. Notch 1 and Notch 3 have been described as tumor suppressor genes in PTC, FTC and ATC (Xiao et al. 2009, Yu et al. 2013, Somnay et al. 2017). Moreover, Notch1 and 3 expression are inversely correlated to the degree of differentiation in thyroid cancers with ATC having the strongest decreased expression of both Notch (Ferretti et al. 2008, Somnay et al. 2017). From a clinical point of view, low Notch3 expression levels correlated with overall survival independently from the classical, other prognostic factors (Somnay et al. 2017). In vitro Notch3 constitutive activation in a FTC cell line increased the mRNA levels of thyroid specific genes, that is, NIS, TSH-R, TTF-1 and TTF-2. In a non-tumoral context, in the normal FRTL-5 rat thyroid cell line, overexpression of Notch1 increased 
the expression of NIS and TPO (Ferretti et al. 2008). Pharmacological Notch1 activating compounds (Fig. 2) such as resveratrol (Yu et al. 2013) or Hesperetin (Patel et al. 2014) have been shown to induce NIS mRNA levels or other differentiation markers such as TSH-R, TTF-1, TTF-2 and PAX8, in vitro in ATC cell lines. The silencing of Notch 1 by siRNA abrogated this effect, demonstrating the dependence upon Notch1 signaling (Yu et al. 2013). Interestingly other compounds with redifferentiation capacity, such as the HDAC inhibitors valproic acid and SAHA or retinoic acid outlined elsewhere in these reviews have also been reported as Notch activating compounds (Lin et al. 2003, Xiao et al. 2009).

\section{PDGFR $\alpha$ blockade}

Lopez-Campistrous et al. (2016) have demonstrated in thyroid cancer cell lines and mouse xenograft models that activation of PDGFR $\alpha$ decreases Tg and NIS expression which promotes a decrease in radioiodine uptake (Fig. 2). Blocking PDGFR $\alpha$ in these same models improved radioiodine uptake and also reduced migration and invasion potentials of the cells as well as tumor volume in animal models. The relocation of the transcription factor TTF1 from the nucleus to the cytoplasm is the main mechanism of action of PDGFR $\alpha$ activation. In human PTC, PDGFR $\alpha$ expression was strongly associated with metastatic disease and radioiodine resistance.

\section{Modulation of NIS transcription}

Epigenetic modification is responsible for the regulation of gene expression without involving modification of the genomic DNA sequence. Epigenetic dysregulation is emerging as a contributor to carcinogenesis and tumor progression and as a therapeutic target. The restoration of iodine uptake in thyroid tumors that were considered refractory to radioiodine, suggesting reversible repression of the SLC5A5 gene encoding for the NIS, is an indirect demonstration of an epigenetic regulation of the NIS gene.

\section{Retinoic acid}

Retinoids are chemical compounds related to vitamin A. They act on the nuclear receptors retinoic acid receptor (RAR) and retinoid X receptor (RXR). All-trans-retinoic acid (RA)-RAR or RA-RXR complexes bind to the responsive elements in gene promoter sites and activate the transcription of their target genes. The retinoid pathway is involved in cellular differentiation, proliferation and apoptosis. Retinoic acid is a well-known drug for certain dermatological diseases.

In thyroid carcinoma cell lines, in vitro experiments showed that retinoids affect thyroid specific functions (induction of type I 5'-deiodinase activity, NIS gene expression), cell-cell or cell-matrix interaction, differentiation markers, growth and tumorigenicity (Van Herle et al. 1990, Schreck et al. 1994, Kurebayashi et al. 2000, Schmutzler \& Kohrle 2000, Schmutzler et al. 2002, Jeong et al. 2006). Moreover, retinoids partly re-differentiate follicular thyroid carcinoma cell lines (Schmutzler \& Kohrle 2000) (Fig. 2).

The first clinical series of ten RAIR-DTC patients treated with isotretinoin (13-cis-retinoid acid, a firstgeneration retinoid) was published by Simon et al. Radioiodine uptake was restored in four patients (Simon et al. 1996). Other pilot studies reported an increase in radioiodine uptake in about 20 to $40 \%$ of patients (Grunwald et al. 1994, Simon et al. 2002, Gruning et al. 2003, Courbon et al. 2006, Fernandez et al. 2009, Kim et al. 2009, Oh et al. 2011). However, tumor response did not always correlate with increased radioiodine uptake and other direct antiproliferative effects of isotretinoin might have been involved (Simon et al. 2002). Prospective clinical trials failed to demonstrate a clinical utility of isotretinoin. In an open-label phase II trial, isotretinoin did not significantly increase radioiodine uptake in 16 RAIR-DTC (Short et al. 2004). In another published phase II trial, increased radioiodine uptake was observed in $17 \%$ ( $n=9 / 53)$ of patients. However, this did not translate into tumor response or clinical benefit (Handkiewicz-Junak et al. 2009).

Few clinical data exist with other retinoids. In a series of 11 patients treated with tretinoin (all-trans-retinoic acid (RA)), also a first-generation retinoid, authors reported increased radioiodine uptake in four patients and partial response in five patients (Zhang et al. 2007). Another series of 13 patients treated with tretinoin for RAIR-DTC showed a weak radioiodine uptake in six patients, with no tumor response among those patients (Damle et al. 2011). In a pilot study with bexarotene (RXR activator), increased radioiodine uptake was observed in 8/11 patients, but no significant clinical benefit was demonstrated (Liu et al. 2006a).

A recent meta-analysis on retinoids in RAIR-DTC reported a pooled effect of $27.6 \%$ for increased radioiodine uptake and $17 \%$ for tumor response by RECIST criteria (Pak et al. 2018). 


\section{HDAC inhibitors}

Post-translational modification of histones bound to DNA such as acetylation is a well-known mechanism of tumorigenesis initiation and progression, especially for thyroid cancers (Russo et al. 2013). By altering the structural state of chromatin, histone acetylation by histone acetyl transferases favors transcriptional activation. On the other hand, histone deacetylation by histone deacetylase (HDACs) is associated with transcriptional repression. Several publications have demonstrated that the acetylation of histones of the SLC5A5 promotor regulates its transcription and consequently NIS expression (Puppin et al. 2012, Zhang et al. 2014, Fu et al. 2019). Various HDAC inhibitors (HDACi), such as panobinostat (Pugliese et al. 2013, Wachter et al. 2018a,c, Fu et al. 2019), valproic acid (Shen et al. 2005, Frohlich et al. 2009, Haghpanah et al. 2014, Massimino et al. 2018), vorinostat (Puppin et al. 2005, 2012, Hou et al. 2010, Clinckspoor et al. 2011, Cheng et al. 2016, Wachter et al. 2018a), romidepsin (Kitazono et al. 2001, Furuya et al. 2004, Xu \& Hershman 2006), sodium butyrate (Puppin et al. 2005), Trichostatin A (Zarnegar et al. 2002, Wachter et al. 2018a) or analogs targeting HDAC (Jang et al. 2015), have been shown in human thyroid cancer derived cell lines or patientderived thyroid cancer tissue to reinduce NIS mRNA levels (Fig. 2) or even other thyroid differentiation genes such as Tg, TPO or TSH receptor. More interestingly, some studies have demonstrated in cellular or in in vivo models an increase in iodine uptake following HDACi treatment and/or proper targeting of the NIS to the plasma membrane where this transporter can be effective (Kitazono et al. 2001, Furuya et al. 2004, Hou et al. 2010, Puppin et al. 2012, Pugliese et al. 2013, Cheng et al. 2016, Massimino et al. 2018, Wachter et al. 2018a, Fu et al. 2019). However, the results of four clinical trials (Kelly et al. 2005, AmiriKordestani et al. 2013, Sherman et al. 2013, Nilubol et al. 2017) that tested HDACi in RAIR human thyroid cancers were in apparent contradiction with the promising results of preclinical studies. Nilubol et al. (2017) tested the effect of valproic acid in 13 patients with RAIR DTC without any improvement in radioiodine uptake in the ten patients evaluable. Two trials have tested romidepsin (AmiriKordestani et al. 2013, Sherman et al. 2013) in RAIR DTC. In these phase 1 and 2 trials, the 131I diagnostic WBS showed restoration of faint radioiodine uptake after various time periods of treatment in two out of six evaluable patients for the phase 1 study and 2 out of 16 patients for the phase 2. In the phase 2 trial (Sherman et al. 2013), the faint radioiodine uptake observed on the diagnostic WBS was confirmed on the therapeutic WBS but without longterm benefit from the treatment. In a phase 1 trial testing vorinostat, also known as Suberoylanilide Hydroxamic Acid (SAHA) (Kelly et al. 2005), in patients with advanced thyroid cancers, Kelly et al. reported an improvement in the radioiodine uptake evaluated by post-therapeutic WBS after SAHA administration for an unknown duration in one out of the three PTC patients included. These trials have classically been considered disappointing. However, several points should be highlighted before definitively buring HDACi as an effective redifferentiation strategy. First, from a clinical point of view, besides the small number of patients included that preclude any definite conclusion, the evaluation of a proper iodine uptake increase or restoration after HDACi treatment on a diagnostic WBS can be criticized as this imaging lacks sensitivity (Haugen et al. 2016). Second, preclinical studies show the complexity of triggering NIS and other thyroiddifferentiation gene reinduction. In several of these studies the redifferentiation effect, that is, the increase in NIS mRNA and/or protein levels and/or increase in iodine uptake, was considerably variable among the human thyroid cancer-derived cell lines tested, suggesting variable effects according to the genetic background of the cell lines (Shen et al. 2005, Clinckspoor et al. 2011, Massimino et al. 2018, Fu et al. 2019). Illustrating the fine and complex regulation of the system, Shen et al. (2005) reported a paradoxical inefficacy to restore NIS mRNA levels of a higher dose of valproic acid (1.5 mM) in comparison with a lower dose $(0.5 \mathrm{mM})$. Moreover, the timing of HDACi administration and the evaluation of the redifferentiation effect might also be critical, as in vitro the increase in radioiodine uptake may vary with the timing of the pharmacological inhibitor administration (Wachter et al. 2018c).

Several publications suggest that drug combination may be a powerful redifferentiation strategy. MAPK inhibition with a MEK inhibitor or a BRAFV600E inhibitor combined with HDACi, such as panobinostat or SAHA, has been shown to have a synergistic effect on NIS and other differentiation thyroid gene (TSH-R, TPO, Tg) reinduction in various human thyroid cancer cell lines, in comparison with either drug used alone (Hou et al. 2010, Cheng et al. 2016, Fu et al. 2019). This effect was even further enhanced by treatment with TSH, which not only enhanced the expression of thyroid genes but also promoted NIS targeting to the plasma membrane (Hou et al. 2010, Cheng et al. 2016). PI3K pathway inhibitors, such as mTOR or Akt inhibitors, in combination with HDACi also have the same synergistic effect (Hou et al. 2010). 
Finally, the triple combination of MEK inhibitor, Akt inhibitor and SAHA had a synergistic effect on radioidine uptake, further enhanced by TSH, in human ATC derived cell lines (Hou et al. 2010). These pre-clinical data provide evidence which supports the proposal to use a drug combination strategy targeting the MAPK pathway and/or PI3K pathway with HDACi.

Finally, beyond HDACi, a poly ADP ribose polymerase-1 (PARP-1) pharmacological inhibitor has been demonstrated to increase radioiodine uptake in different thyroid cancer cell lines, through upregulation of histone modification activation marks, especially the acetylation of lysine 9 and 14 of histone 3 (H3K9K14Ac) (Lavarone et al. 2013).

\section{PPAR $\gamma$ agonists}

Peroxisome proliferator-activated receptor (PPAR)- $\gamma$ belongs to the nuclear receptor family of transcription factors. PPAR- $\gamma$ is the master regulator of adipogenesis and plays a role in tumorigenesis (Raman \& Koenig 2014). Of note, the rearrangement of PPAR- $\gamma / \mathrm{PAX} 8$ occurs in $30-35 \%$ of FTC and in some follicular variants of PTC (Raman \& Koenig 2014).

Different pre-clinical studies have demonstrated the re-differentiation effect of several thiazolidinediones, which bind to PPAR $\gamma$ and are known to be PPAR $\gamma$ agonists, such as rosiglitazone (Frohlich et al. 2005, 2009, troglitazone (Park et al. 2005) and pioglitazone (Frohlich et al. 2005), in addition to their anti-proliferative effects on DTC-derived cell lines (Fig. 2). Interestingly, Frohlich et al. (2005) demonstrated that, in FTC cell lines, thiazolidinediones increased radioiodine uptake and the amount of NIS in the membrane fraction, especially troglitazone which showed greater effects than other thiazolidinediones. However, these effects seem to be independent of PPAR $\gamma$ activation, as the addition of a PPAR $\gamma$ antagonist did not reverse their effects.

Several case reports (Elias \& Lizotte 2006, Elola et al. 2011), pilot study and phase II clinical trials (Philips et al. 2004, Kebebew et al. 2006, 2009, Tepmongkol et al. 2008, Rosenbaum-Krumme et al. 2012) suggest a more or less efficient re-differentiation effect of the PPAR $\gamma$ agonist rosiglitazone. Kebebew et al. (2006, 2009) published the results of a phase II trial including 20 patients with RAIR DTC treated for 8 weeks with rosiglitazone of whom four showed a positive diagnostic WBS after treatment. Despite the administration of 50 to $213 \mathrm{mCi}$ I131 in those four patients, none had complete or even partial response according to the RECIST 1.1 criteria at 3 months of follow-up. There was no relationship between the level of PPAR $\gamma$ mRNA and protein expression in patients who had radioiodine uptake compared with those who did not. These last results were in contradiction with the study of Tepmongkol et al. (2008). Out of 23 patients with RAIR DTC treated for 6 weeks with rosiglitazone, six patients demonstrated restoration of radioiodine uptake on a therapeutic WBS after rosiglitazone. Of these, five had strong PPAR $\gamma$-positive staining in thyroid biopsies and one a weak staining. On the other hand, none of the seven patients with negative staining had positive therapeutic WBS after rosiglitazone therapy. In the study of Rosenbaum-Krumme et al. (2012), out of nine patients, four were retreated after 3 or 6 months of rosiglitazone and, of these, three had best partial response using RECIST 1.1 criteria after rosiglitazone therapy. A small pilot study in 2004 (Philips et al. 2004) had shown less encouraging results than the trials described, as out of five patients with RAIR DTC, only one experienced restoration of a faint uptake of radioiodine in lung metastases after 3 months of rosiglitazone.

\section{Pre-clinical data for potential future targets}

\section{Demethylating agents}

Hypermethylation of the promoter region of the SCLC $5 A 5$ gene encoding for the NIS have been demonstrated in several publications, both in benign and malignant thyroid tumors (Venkataraman et al. 1999, Xing et al. 2003, Smith et al. 2007, Stephen et al. 2011, Galrao et al. 2013, 2014) (Fig. 2). In PTC, specific CpG-island regions of the promoter are hypermethylated through DNA methyltransferase 1 (DNMT1) up-regulation following NFkB activation by BRAFV600E (Choi et al. 2014). Moreover, an inverse correlation between NIS expression and the degree of methylation of some of this CpG island has been described (Galrao et al. 2014). However, preclinical studies analyzing the re-dedifferentiation effect of demethylating agents such as 5 -azacytidine in human thyroid cancer cell lines had shown disappointing results without any significant effect on NIS mRNA reinduction and/or radioiodine uptake increase (Provenzano et al. 2007, Tuncel et al. 2007, Massimino et al. 2018), unless 5 -azacytidine was associated with the sodium butyrate HDACi (Provenzano et al. 2007). Only one study showed an increase in radioiodine uptake in vitro after 5-azacytidine treatment, correlated with a reduced methylation level of SCLC5A5 promoter (Galrao et al. 2014). To date, clinical trials evaluating demethylating agent effects on RAIR DTC redifferentiation are still lacking. 


\section{NADPH oxidase 4 (NOX4)}

The link between BRAFV600E mutation, reduction of NIS expression and dedifferentiation is well established. Even if a link between BRAFV600E-induced TGF $\beta$ production and repression of NIS, Tg and TPO has been demonstrated (Kawaguchi et al. 1997, Nicolussi et al. 2003, Costamagna et al. 2004, Riesco-Eizaguirre et al. 2006), the whole underlying molecular mechanism remains largely unknown. Azouzi et al. (2017) shed light on the role of the NADPH oxidase NOX4, an enzyme specialized in reactive oxygen species production upregulated in thyroid cancers (Weyemi et al. 2010). Azouzi et al. demonstrated that NOX4 upregulation by the BRAFV600E_ activated TGF $\beta$-Smad3 pathway correlated with NIS repression and dedifferentiation in thyroid cancer cell lines, patient tissue samples and in mouse BRAFV600E_ induced thyroid tumors. Remarkably NOX4 silencing by siRNA reversed BRAFV600E-induced NIS repression at the mRNA and protein levels, making NOX4 a potential future therapeutic target (Fig. 2).

Consistent with this data, the antioxidant alphalipoic acid was able to increase radioiodine uptake in a human thyroid cancer derived cell line (Choi et al. 2012).

\section{Bromodomain-containing protein 4 (BRD4)}

BRD4 is a member of the BET (bromodomain and extra terminal) family which binds to acetylated histones promoting gene transcription and plays a role in carcinogenesis. BRD4 is up-regulated in thyroid cancer tissues and cell lines (Gao et al. 2016) and its pharmacological inhibition, besides having an antiproliferative effect, restored radioiodine uptake in thyroid cancer cell lines and in a mouse model of human papillary xenograft (Gao et al. 2016) (Fig 2).

\section{Digitalis-like components}

Autophagy, which facilitates the degradation of cytoplasmic components in response to stimuli such as DNA damage or hypoxia, has emerged as a key player in carcinogenesis. In thyroid cancers, autophagy has been shown to be associated with dedifferentiation and reduced clinical response to radioiodine (Plantinga et al. 2016). Based on this association, a systematic high-throughput screening has identified autophagy-activating digitalislike compounds capable of restoring NIS expression and iodine uptake, at micromolecular concentrations, in PTC, FTC (Tesselaar et al. 2017) and ATC cell lines (Tesselaar et al. 2018) (Fig. 2). The increase in transcriptional activation of NIS following up-regulation of transcription factors such as FOS or ATF3 (activating transcription factor 3) (Tesselaar et al. 2017, 2018) after digitalis-like compound treatment may account for the redifferentiation effect. Future studies involving mouse models and addressing the issue of the narrow therapeutic index of digitalis-like compounds as well as the dosage required for thyroid cancer redifferentiation are mandatory before clinical implementation.

\section{Modulation of NIS trafficking to the plasma membrane}

The restoration of NIS expression in RAIR thyroid cancers can be insufficient as NIS targeting to the plasma membrane can be impaired (Fig. 1). Interestingly, overexpression of BRAFV600E in normal rat PCCL3 thyroid cells has the same effect as TSH withdrawal from the culture medium, that is, besides decreasing NIS protein levels, it also impairs NIS targeting to the plasma membrane (Riesco-Eizaguirre et al. 2006). Inhibition of the MAPK pathway by a MEK inhibitor partially restored NIS protein expression, albeit without recovering proper localization to the plasma membrane (Riesco-Eizaguirre et al. 2006).

Regarding the issue of the sub-cellular localization of NIS, several publications have shed light on the role of the proto-oncogene pituitary tumor transforming gene (PTTG)-binding factor (PBF) which may represent a novel therapeutic target for increasing radioiodine uptake (Smith et al. 2011). PBF, which specifically binds to PTTG, is over-expressed in thyroid cancers (Smith et al. 2011). After its phosphorylation on a tyrosine residue by the kinase Src, PBF represses iodide uptake in vitro and in murine models (Read et al. 2011) through two mechanisms: transcriptional inhibition of NIS expression (Boelaert et al. 2007) and the binding and redistribution of the NIS from the plasma membrane to the cytoplasm (Smith et al. 2009). Interestingly, a pharmacological Src inhibitor was able to stimulate radioiodine uptake in human thyroid cancer cell lines and in human primary thyroid cells (Smith et al. 2013). Future clinical therapeutic strategies may combine drugs targeting NIS protein reinduction associated with drugs modulating NIS sub-cellular localization, more specifically to the plasma membrane where the NIS is fully active.

Moreover, Thompson et al. (2019) recently demonstrated in vitro that NIS dimerization may be critical to its trafficking to the plasma membrane. Impaired dimerization of the NIS and its subsequent 
mis-localization in RAIR DTC remains a field for future investigation.

Lan et al. (2017) demonstrated that $\beta$-catenin activation subsequent to HIF1 $\alpha$ overexpression relocated the NIS into intracellular location near the nucleus in FTC cells. As a consequence, radioiodine uptake decreased, but $\beta$-catenin knockdown restored the iodine uptake capacity and the NIS localization on the periphery of the cells. Experiments in xenograft mice tumors confirmed these data, as $\beta$-catenin silencing promotes the efficacy of radioiodine therapy in FTC cells overexpressing HIF-1 $\alpha$ and $\beta$-catenin.

Finally, two novel NIS interactors namely ARF4 (ADPribosylation) and VCP (valosin-containing protein) have been involved in NIS trafficking to the plasma membrane. ARF4 enhanced NIS trafficking to the plasma membrane, while VCP governed NIS proteolysis. ARF4 overexpression and VCP inactivation resulted in increased iodine uptake in human thyroid cancer cells. Selective VCP inhibitors promoted RAI uptake in these same models as well as in primary thyrocytes isolated from a mouse model. Interestingly VCP and ARF4 are associated with poorer survival characteristics in RAI-treated patients (Fletcher et al. 2019).

\section{Modulation of NIS post-transcriptional regulation}

Few data are published on the role of miRNA, which are small interfering RNAs modulating the translation, on NIS and other thyroid differentiation genes expression.

Among the miRNA studied, the following ones appear to be good candidates to modulate NIS expression: miR-146b, miR-let-7f-5p, miR-21 and miR-106a (Shen et al. 2005, Li et al. 2015, Riesco-Eizaguirre et al. 2015, Damanakis et al. 2016, Haghpanah et al. 2016, Wachter et al. 2018b). Interestingly, in the TCGA miR-146b-5p, miR-146b-3p and miR-21 were inversely correlated with the thyroid differentiation score of the PTC studied (Cancer Genome Atlas Research 2014).

\section{Gene therapy}

Using various delivery techniques, radioiodine uptake was induced in vitro in different thyroid cancer cell lines and sometimes in vivo in xenograft models by NIS gene delivery and reviewed in 2009 by Sptizweg (Spitzweg 2009).
All studies (Smit et al. 2000, Haberkorn et al. 2003, Lee et al. 2003, Lin et al. 2004) demonstrated that NIS gene therapy was able to increase radioiodine uptake but almost always along with rapid iodide efflux which, as a consequence, was not sufficient to allow the therapeutic effects of radioiodine in vivo in animal models, except in one study (Smit et al. 2002).

Other studies suggested that gene therapy with both the transcription factors TTF1 and PAX8, known to control the expression of the NIS gene as well as Tg and TPO, was able to induce radioiodine uptake in thyroid cancer cell lines and could limit radioiodine efflux, while gene therapy with the transcription factor TTF1 alone was associated with rapid iodine efflux ( $\mathrm{Mu}$ et al. 2012). The adenovirus mediated transfer of TTF1 in thyroid cancer cell lines that also stably express the NIS rescued this rapid radioiodine efflux issue (Furuya et al. 2004). Pax-8 gene transfer alone in thyroid cancer cell lines seems to be sufficient to promote radioiodine uptake and prolonged retention of radioiodine through up-regulation of NIS, TPO and Tg expression (Mu et al. 2012).

NIS gene transfer driven by telomerase promoters in a human thyroid cancer cell line markedly reduced cell viability after exposure to radioiodine (Riesco-Eizaguirre et al. 2011).

Finally, based on EGFR overexpression in ATC, EGFRtargeted synthetic polymers were used to target NIS expression in ATC cell lines as well as in DTC cell lines (Schmohl et al. 2017). Radioiodine uptake was significantly increased in vitro and in vivo in a mouse xenograft model, leading to significant reduction in tumor growth and prolonged survival in comparison with control animals.

\section{Other potential strategies}

A south Korean group recently published three papers describing the potential of the inverse agonist of estrogenrelated receptor $(\mathrm{ERR} \gamma)$ on the redifferentiation of thyroid tumors (Singh etal. 2015, 2019, Kim et al. 2019). The inverse agonist of ERR $\gamma$ increased radioiodine uptake in ATC cell lines by inducing the expression of iodine handling genes and by enhancing the membrane localization of the NIS (Singh et al. 2015, 2019, Kim et al. 2019). Surprisingly, pharmacological MEK inhibitors abolished the effects of the inverse agonist of ERR $\gamma$ on radioiodine uptake of the cells (Singh et al. 2015, 2019). Moreover, one orally active inverse agonist of ERR $\gamma$ has also been demonstrated in vivo in xenograft tumor mice models of ATC to increase
C) 2020 Society for Endocrinology Published by Bioscientifica Ltd. Printed in Great Britain 
radioiodine activity and reduction of tumor growth after radioiodine therapy (Singh et al. 2015, 2019).

TERT (telomerase reverse transcriptase) may be another potential candidate, as the mutation of its promoter are more prevalent in the less differentiated form of thyroid cancers, that is, PDTC and ATC (Landa et al. 2016), and are associated with a decrease in NIS mRNA levels in an analysis of the TCGA database (Tavares et al. 2018). Moreover, different studies suggest that TERT promoter mutation alone is associated with a loss of radioiodine avidity and even more so when associated with BRAFV600E mutation (Yang et al. 2017, Liu et al. 2019).

Lithium salts known to increase the trapping of iodide by the thyroid glands showed inconsistent and disappointing results in term of potentiation of radioiodine uptake in benign thyroid diseases and DTC in clinical series (Liu et al. 2006b).

Other miscellaneous studies have highlighted the potential of other agents as candidates for redifferentiation strategy (Marsee et al. 2004, Goncalves et al. 2013, 2018, Liu et al. 2017, Bauriaud-Mallet et al. 2019, Chai et al. 2019, Vella et al. 2019).

\section{Perspectives and concluding remarks}

The differentiation of follicular cells and more particularly the expression of the NIS and the iodide-metabolizing machinery is subject to very complex regulation. The data discussed in this review are promising for the redifferentiation of DTC and there is even hope for the redifferentiation of ATC. The redifferentiation of thyroid cancers offers the hope of obtaining prolonged remission or even cure of the disease, similar to what is observed for radioiodine avid metastatic thyroid cancers. However, there is neither long-term follow-up in any of the trials or case reports published nor data on repeated treatment and many issues remain to be addressed to optimize the redifferentiation approach.

The strategy to adopt and the objectives to achieve remain an open question. Three different scenarios are possible:

- The first would be a redifferentiation strategy implemented in the case of a RAIR DTC with a low metastatic tumoral volume (i.e. lesions under $1 \mathrm{~cm}$ ) slowly progressing to achieve very prolonged stability of the disease or even remission.

- The second scenario would be a redifferentiation strategy implemented in the case of a RAIR DTC with a significant progressive metastatic tumoral volume (i.e. multiple lesions above $1 \mathrm{~cm}$ ) to achieve stability of the disease or even a response to the strategy synergistically with the effect of antiproliferative systemic therapies.

- A third scenario of optimizing radioiodine uptake in thyroid cancer has emerged in the adjuvant situation after thyroid surgery and before the first radioiodine therapy for selected high risk DTC patients who present persistent/recurrent disease in 30 to $60 \%$ of the cases.

In all scenarios, as already mentioned, the timing of redifferentiating drug administration before new radioiodine treatment is a key element for the success of radioiodine uptake restoration. The future is certainly to move toward strategies combining two or more drugs with a complementary mechanism of action, that is, drugs inhibiting the MAPK pathway output combined with drugs acting on the epigenetic regulation of the NIS and drugs that target the NIS to the plasma membrane for example. However, many other combinations could be considered. To address the side effect counterpart of these multiple combinations, the challenge is to find the minimal time period required to redifferentiate tumor cells and find the most efficient combination of drugs. In this context, novel data on the redifferentiation potential of the latest generation of well-tolerated and highly selective RET or NTRK inhibitors may emerge. To this end, recent tools such as ${ }^{124}$ I PET/CT make a dosimetric approach possible and, when performed sequentially, could also be powerful in determining the optimal timing of drug administration before radioiodine therapy. Other clinical studies propose qualitative evaluations with 123-iodine SPECT/CT or diagnostic 131-iodine WBS and a fixed dose of $150 \mathrm{mCi}$ of 131-iodine in patients with increased uptake after MEK or BRAF inhibitors with comparable efficiency. In the future, these different strategies need to be correctly evaluated with direct comparisons in trials dedicated to this in order to prove the superiority of the dosimetric approach from a clinical point of view.

The question of whether to discontinue one or more redifferentiating drugs after radioiodine treatment remains to be answered, except for the third scenario (in the adjuvant setting) in which obviously redifferentiating treatments can be stopped after the administration of radioiodine. This raises the issue of the efficacy per se of radioiodine uptake increase or restoration vs the antiproliferative effect of systemic drugs used. However, in the first scenario of a low metastatic volume (i.e. lesions under $1 \mathrm{~cm}$, based on RECIST measurability criteria usually taken into account for long term systemic 
treatment introduction), with slow progression, the benefit over the risk ratio may be in favor of discontinuing the redifferentiating drugs. In this scenario, management would involve the administration of a shot of redifferentiating drugs for a minimum period followed by radioiodine therapy and discontinuation of the drugs. In the second scenario, systemic therapies may be continued in between radioiodine sessions. It is not described whether the continuation of systemic treatments could be associated with a loss of the redifferentiating effect and whether the temporary interruption of treatments followed by their recovery could be beneficial to this end.

Regarding the selection of the best candidates for redifferentiation strategy, several issues arise. Is there a need for imaging to evaluate the potential of iodine uptake and, if there is, what is the degree of this uptake to select patients for treatment with a therapeutic dose of radioiodine? What are the predictive factors of redifferentiation? A simple and reliable biochemical marker of redifferentiation is probably the increase in the plasmatic Tg level without morphological tumoral progression or even with a decrease in tumoral metastatic volume. Besides Tg level, is there a molecular profile able to predict responders to the redifferentiation strategy? Could plasma drug level monitoring be useful in improving redifferentiation strategy and in identifying responders? The identification of predictive factors of redifferentiation is a main field on the agenda for future research, especially when considering this strategy in adjuvant setting, where the benefit over the risk ratio should be carefully weighed up.

To conclude, at the time of redifferentiation strategy, the definition of RAIR thyroid cancers should be revisited. After the administration of redifferentiating drugs, three scenarios could be identified:

- Restored radioiodine responsive patients: an ideal situation where radioiodine uptake is increased or restored along with an objective radiological prolonged stabilization or a decrease in a progressive metastatic tumoral mass.

- True radioiodine resistance: a situation where there is a radioiodine uptake increase or restoration but with a radiological progression of the metastatic tumoral mass. In this case, the molecular mechanism underlying the resistance to radioiodine remains unclear.

- Persistent non avid patients: a situation where there is failure to restore radioiodine uptake. In this case, the molecular mechanism underlying the absence of a correct restoration of NIS activity remains to be elucidated.
In conclusion, redifferentiation strategy provides hope for the major issue of long-term adverse events of systemic therapies currently used for RAIR-DTC, thus creating new opportunities and a new choice for metastatic patients who should be back at the center of the decision-making process.

\section{Declaration of interest}

The authors declare that there is no conflict of interest that could be perceived as prejudicing the impartiality of this review.

\section{Funding}

This work did not receive any specific grant from any funding agency in the public, commercial or not-for-profit sector.

\section{References}

Ahuja S, Avram AM, Dillehay G, Greenspan BS, Gulec S \& Van Nostrand D 2019 The Martinique principles. Journal of Nuclear Medicine 60 1334-1335. (https://doi.org/10.2967/ jnumed.119.232066)

Amiri-Kordestani L, Luchenko V, Peer CJ, Ghafourian K, Reynolds J, Draper D, Frye R, Woo S, Venzon D, Wright J, et al. 2013 Phase I trial of a new schedule of Romidepsin in patients with advanced cancers. Clinical Cancer Research 19 4499-4507. (https://doi. org/10.1158/1078-0432.CCR-13-0095)

Azouzi N, Cailloux J, Cazarin JM, Knauf JA, Cracchiolo J, Al Ghuzlan A, Hartl D, Polak M, Carre A, El Mzibri M, et al. 2017 NADPH oxidase NOX4 is a critical mediator of BRAF(V600E)-induced downregulation of the sodium/iodide symporter in papillary thyroid carcinomas. Antioxidants and Redox Signaling 26 864-877. (https://doi. org/10.1089/ars.2015.6616)

Bauriaud-Mallet M, Vija-Racaru L, Brillouet S, Mallinger A, De Medina P, Rives A, Payre B, Poirot M, Courbon F \& Silvente-Poirot S 2019 The cholesterol-derived metabolite dendrogenin A functionally reprograms breast adenocarcinoma and undifferentiated thyroid cancer cells. Journal of Steroid Biochemistry and Molecular Biology 192 105390. (https://doi.org/10.1016/j.jsbmb.2019.105390)

Boelaert K, Smith VE, Stratford AL, Kogai T, Tannahill LA, Watkinson JC, Eggo MC, Franklyn JA \& Mccabe CJ 2007 PTTG and PBF repress the human sodium iodide symporter. Oncogene 26 4344-4356. (https:// doi.org/10.1038/sj.onc.1210221)

Brown SR, Hall A, Buckley HL, Flanagan L, Gonzalez de Castro D, Farnell K, Moss L, Gregory R, Newbold K, Du Y, et al. 2019 Investigating the potential clinical benefit of selumetinib in resensitising advanced iodine refractory differentiated thyroid cancer to radioiodine therapy (SEL-I-METRY): protocol for a multicentre UK single arm phase II trial. BMC Cancer 19 582. (https://doi. org/10.1186/s12885-019-5541-4)

Cancer Genome Atlas Research Network 2014 Integrated genomic characterization of papillary thyroid carcinoma. Cell 159 676-690.

Chai W, Ye F, Zeng L, Li Y \& Yang L 2019 HMGB1-mediated autophagy regulates sodium/iodide symporter protein degradation in thyroid cancer cells. Journal of Experimental and Clinical Cancer Research $\mathbf{3 8}$ 325. (https://doi.org/10.1186/s13046-019-1328-3)

Chakravarty D, Santos E, Ryder M, Knauf JA, Liao XH, West BL, Bollag G, Kolesnick R, Thin TH, Rosen N, et al. 2011 Small-molecule MAPK inhibitors restore radioiodine incorporation in mouse thyroid
C) 2020 Society for Endocrinology Published by Bioscientifica Ltd. Printed in Great Britain 
cancers with conditional BRAF activation. Journal of Clinical Investigation 121 4700-4711. (https://doi.org/10.1172/JCI46382)

Cheng W, Liu R, Zhu G, Wang H \& Xing M 2016 Robust thyroid gene expression and radioiodine uptake induced by simultaneous suppression of BRAF V600E and histone deacetylase in thyroid cancer cells. Journal of Clinical Endocrinology and Metabolism 101 962-971. (https://doi.org/10.1210/jc.2015-3433)

Cheng L, Jin Y, Liu M, Ruan M \& Chen L 2017 HER inhibitor promotes BRAF/MEK inhibitor-induced redifferentiation in papillary thyroid cancer harboring BRAFV600E. Oncotarget 8 19843-19854. (https:// doi.org/10.18632/oncotarget.15773)

Choi HJ, Kim TY, Ruiz-Llorente S, Jeon MJ, Han JM, Kim WG, Shong YK \& Kim WB 2012 Alpha-lipoic acid induces sodium iodide symporter expression in TPC-1 thyroid cancer cell line. Nuclear Medicine and Biology 39 1275-1280. (https://doi.org/10.1016/j. nucmedbio.2012.08.007)

Choi YW, Kim HJ, Kim YH, Park SH, Chwae YJ, Lee J, Soh EY, Kim JH \& Park TJ 2014 B-RafV600E inhibits sodium iodide symporter expression via regulation of DNA methyltransferase 1. Experimental and Molecular Medicine 46 e120. (https://doi.org/10.1038/ emm.2014.68)

Clinckspoor I, Verlinden L, Overbergh L, Korch C, Bouillon R, Mathieu C, Verstuyf A \& Decallonne B 2011 1,25-Dihydroxyvitamin D3 and a superagonistic analog in combination with paclitaxel or suberoylanilide hydroxamic acid have potent antiproliferative effects on anaplastic thyroid cancer. Journal of Steroid Biochemistry and Molecular Biology 124 1-9. (https://doi.org/10.1016/j. jsbmb.2010.12.008)

Costamagna E, Garcia B \& Santisteban P 2004 The functional interaction between the paired domain transcription factor Pax8 and Smad3 is involved in transforming growth factor-beta repression of the sodium/iodide symporter gene. Journal of Biological Chemistry 279 3439-3446. (https://doi.org/10.1074/jbc.M307138200)

Courbon F, Zerdoud S, Bastie D, Archambaud F, Hoff M, Eche N, Berry I \& Caron P 2006 Defective efficacy of retinoic acid treatment in patients with metastatic thyroid carcinoma. Thyroid 16 1025-1031. (https://doi.org/10.1089/thy.2006.16.1025)

Damanakis AI, Eckhardt S, Wunderlich A, Roth S, Wissniowski TT, Bartsch DK \& Di Fazio P 2016 MicroRNAs let7 expression in thyroid cancer: correlation with their deputed targets HMGA2 and SLC5A5. Journal of Cancer Research and Clinical Oncology 142 1213-1220.

Damle N, Patnecha M, Kumar P, Maharjan S \& Bal C 2011 Retinoic acid therapy in patients with radioiodine negative differentiated thyroid cancer and clinical or biochemical evidence of disease: an initial experience. Indian Journal of Nuclear Medicine 26 144-148. (https:// doi.org/10.4103/0972-3919.103997)

De Souza EC, Padron AS, Braga WM, De Andrade BM, Vaisman M, Nasciutti LE, Ferreira AC \& De Carvalho DP 2010 MTOR downregulates iodide uptake in thyrocytes. Journal of Endocrinology 206 113-120. (https://doi.org/10.1677/JOE-09-0436)

Deandreis D, Rubino C, Tala H, Leboulleux S, Terroir M, Baudin E, Larson S, Fagin JA, Schlumberger M \& Tuttle RM 2017 Comparison of empiric versus whole-body/-blood clearance dosimetry-based approach to radioactive iodine treatment in patients with metastases from differentiated thyroid cancer. Journal of Nuclear Medicine $\mathbf{5 8}$ 717-722. (https://doi.org/10.2967/jnumed.116.179606)

Dunn LA, Sherman EJ, Baxi SS, Tchekmedyian V, Grewal RK, Larson SM, Pentlow KS, Haque S, Tuttle RM, Sabra MM, et al. 2019 Vemurafenib redifferentiation of BRAF mutant, RAI-refractory thyroid cancers. Journal of Clinical Endocrinology and Metabolism 104 1417-1428. (https://doi.org/10.1210/jc.2018-01478)

Durante C, Haddy N, Baudin E, Leboulleux S, Hartl D, Travagli JP, Caillou B, Ricard M, Lumbroso JD, De Vathaire F, et al. 2006 Longterm outcome of 444 patients with distant metastases from papillary and follicular thyroid carcinoma: benefits and limits of radioiodine therapy. Journal of Clinical Endocrinology and Metabolism 91 2892-2899. (https://doi.org/10.1210/jc.2005-2838)

Elias AN \& Lizotte P 2006 Enhanced radioiodine uptake in a patient with poorly differentiated papillary thyroid cancer after treatment with rosiglitazone. Clinical Nuclear Medicine 31 517-519. (https://doi. org/10.1097/01.rlu.0000233148.45744.44)

Elmokh O, Taelman V, Radojewski P, Roelli MA, Stoss A, Dumont RA, Dettmer MS, Phillips WA, Walter MA \& Charles RP 2019 MEK inhibition induces therapeutic iodine uptake in a murine model of anaplastic thyroid cancer. Journal of Nuclear Medicine 60 917-923. (https://doi.org/10.2967/jnumed.118.216721)

Elola M, Yoldi A, Emparanza JI, Matteucci T, Bilbao I \& Goena M 2011 Redifferentiation therapy with rosiglitazone in a case of differentiated thyroid cancer with pulmonary metastases and absence of radioiodine uptake. Revista Española de Medicina Nuclear 30 241-243. (https://doi.org/10.1016/j.remn.2010.08.005)

Fenton MS, Marion KM, Salem AK, Hogen R, Naeim F \& Hershman JM 2010 Sunitinib inhibits MEK/ERK and SAPK/JNK pathways and increases sodium/iodide symporter expression in papillary thyroid cancer. Thyroid 20 965-974. (https://doi.org/10.1089/thy.2010.0008)

Fernandez CA, Puig-Domingo M, Lomena F, Estorch M, Camacho Marti V, Bittini AL, Marazuela M, Santamaria J, Castro J, Martinez De Icaya P, et al. 2009 Effectiveness of retinoic acid treatment for redifferentiation of thyroid cancer in relation to recovery of radioiodine uptake. Journal of Endocrinological Investigation $\mathbf{3 2}$ 228-233. (https://doi.org/10.1007/BF03346457)

Ferretti E, Tosi E, Po A, Scipioni A, Morisi R, Espinola MS, Russo D, Durante C, Schlumberger M, Screpanti I, et al. 2008 Notch signaling is involved in expression of thyrocyte differentiation markers and is down-regulated in thyroid tumors. Journal of Clinical Endocrinology and Metabolism 93 4080-4087. (https://doi.org/10.1210/jc.2008-0528)

Fletcher A, Read ML, Thornton CEM, Larner DP, Poole VL, Brookes K, Nieto HR, Alshahrani M, Thompson RJ, Lavery GG, et al. 2019 Targeting novel sodium iodide symporter interactors ADPribosylation factor 4 (ARF4) and valosin-containing protein (VCP) enhances radioiodine uptake. Cancer Research 80 102-115. (https:// doi.org/10.1158/0008-5472.CAN-19-1957)

Frohlich E, Machicao F \& Wahl R 2005 Action of thiazolidinediones on differentiation, proliferation and apoptosis of normal and transformed thyrocytes in culture. Endocrine-Related Cancer 12 291-303. (https://doi.org/10.1677/erc.1.00973)

Frohlich E, Brossart P \& Wahl R 2009 Induction of iodide uptake in transformed thyrocytes: a compound screening in cell lines. European Journal of Nuclear Medicine and Molecular Imaging 36 780-790. (https://doi.org/10.1007/s00259-008-1024-6)

Fu H, Cheng L, Jin Y, Cheng L, Liu M \& Chen L 2019 MAPK inhibitors enhance HDAC inhibitor-induced redifferentiation in papillary thyroid cancer cells harboring BRAFV600E: an in vitro study. Molecular Therapy Oncolytics 12 235-245. (https://doi.org/10.1016/j. omto.2019.01.007)

Furuya F, Shimura H, Suzuki H, Taki K, Ohta K, Haraguchi K, Onaya T, Endo T \& Kobayashi T 2004 Histone deacetylase inhibitors restore radioiodide uptake and retention in poorly differentiated and anaplastic thyroid cancer cells by expression of the sodium/iodide symporter thyroperoxidase and thyroglobulin. Endocrinology 145 2865-2875. (https://doi.org/10.1210/en.2003-1258)

Galrao AL, Sodre AK, Camargo RY, Friguglietti CU, Kulcsar MA, Lima EU, Medeiros-Neto G \& Rubio IG 2013 Methylation levels of sodium-iodide symporter (NIS) promoter in benign and malignant thyroid tumors with reduced NIS expression. Endocrine 43 225-229. (https://doi.org/10.1007/s12020-012-9779-8)

Galrao AL, Camargo RY, Friguglietti CU, Moraes L, Cerutti JM, SerranoNascimento C, Suzuki MF, Medeiros-Neto G \& Rubio IG 2014 Hypermethylation of a New Distal sodium/iodide symporter (NIS) enhancer (NDE) is associated with reduced NIS expression in thyroid (c) 2020 Society for Endocrinology Published by Bioscientifica Ltd. Printed in Great Britain 
tumors. Journal of Clinical Endocrinology and Metabolism 99 E944-E952. (https://doi.org/10.1210/jc.2013-1450)

Gao X, Wu X, Zhang X, Hua W, Zhang Y, Maimaiti Y, Gao Z \& Zhang Y 2016 Inhibition of BRD4 suppresses tumor growth and enhances iodine uptake in thyroid cancer. Biochemical and Biophysical Research Communications 469 679-685. (https://doi.org/10.1016/j. bbrc.2015.12.008)

Garcia B \& Santisteban P 2002 PI3K is involved in the IGF-I inhibition of TSH-induced sodium/iodide symporter gene expression. Molecular Endocrinology 16 342-352. (https://doi.org/10.1210/mend.16.2.0774)

Giuliani C, Noguchi Y, Harii N, Napolitano G, Tatone D, Bucci I, Piantelli M, Monaco F \& Kohn LD 2008 The flavonoid quercetin regulates growth and gene expression in rat FRTL-5 thyroid cells. Endocrinology 149 84-92. (https://doi.org/10.1210/en.2007-0618)

Goncalves CF, Santos MC, Ginabreda MG, Fortunato RS, Carvalho DP \& Freitas Ferreira AC 2013 Flavonoid rutin increases thyroid iodide uptake in rats. PLOS ONE 8 e73908. (https://doi.org/10.1371/journal. pone.0073908)

Goncalves CFL, De Freitas ML, Fortunato RS, Miranda-Alves L, Carvalho DP \& Ferreira ACF 2018 Rutin scavenges reactive oxygen species, inactivates 5 '-adenosine monophosphate-activated protein kinase, and increases sodium-iodide symporter expression in thyroid PCCL3 cells. Thyroid 28 265-275. (https://doi.org/10.1089/ thy.2016.0585)

Gruning T, Tiepolt C, Zophel K, Bredow J, Kropp J \& Franke WG 2003 Retinoic acid for redifferentiation of thyroid cancer - does it hold its promise? European Journal of Endocrinology 148 395-402. (https://doi. org/10.1530/eje.0.1480395)

Grunwald F, Schomburg A, Menzel C, Steinecker S, Spath G, Bockisch A, Fimmers R, Hotze AL \& Biersack HJ 1994 Changes in the blood picture after radioiodine therapy of thyroid cancer. Medizinische Klinik 89 522-528.

Haberkorn V, Oziol L \& Goudonnet H 2003 9-cis-Retinoic acid regulation of four UGT isoforms in hepatocytes from rats with various thyroid states. Pharmaceutical Research 20 1568-1573. (https://doi.org/10.1023/a:1026174931690)

Haghpanah V, Malehmir M, Larijani B, Ahmadian S, Alimoghaddam K, Heshmat R, Ghavamzadeh A, Adabi K \& Ghaffari SH 2014 The beneficial effects of valproic acid in thyroid cancer are mediated through promoting redifferentiation and reducing stemness level: an in vitro study. Journal of Thyroid Research 2014 1-9. (https://doi. org/10.1155/2014/218763)

Haghpanah V, Fallah P, Tavakoli R, Naderi M, Samimi H, Soleimani M \& Larijani B 2016 Antisense-miR-21 enhances differentiation/apoptosis and reduces cancer stemness state on anaplastic thyroid cancer. Tumour Biology 37 1299-1308.

Handkiewicz-Junak D, Roskosz J, Hasse-Lazar K, Szpak-Ulczok S, Puch Z, Kukulska A, Olczyk T, Piela A, Paliczka-Cieslik E \& Jarzab B 2009 13-Cis-retinoic acid re-differentiation therapy and recombinant human thyrotropin-aided radioiodine treatment of non-functional metastatic thyroid cancer: a single-center, 53-patient phase 2 study. Thyroid Research 2 8. (https://doi.org/10.1186/1756-6614-2-8)

Haugen BR, Alexander EK, Bible KC, Doherty GM, Mandel SJ, Nikiforov YE, Pacini F, Randolph GW, Sawka AM, Schlumberger M, et al. 20162015 American Thyroid Association management guidelines for adult patients with thyroid nodules and differentiated thyroid cancer: the American Thyroid Association Guidelines Task Force on thyroid nodules and differentiated thyroid cancer. Thyroid 26 1-133. (https://doi.org/10.1089/thy.2015.0020)

Ho AL, Grewal RK, Leboeuf R, Sherman EJ, Pfister DG, Deandreis D, Pentlow KS, Zanzonico PB, Haque S, Gavane S, et al. 2013 Selumetinib-enhanced radioiodine uptake in advanced thyroid cancer. New England Journal of Medicine 368 623-632. (https://doi. org/10.1056/NEJMoa1209288)

Hoftijzer H, Heemstra KA, Morreau H, Stokkel MP, Corssmit EP, Gelderblom H, Weijers K, Pereira AM, Huijberts M, Kapiteijn E, et al.
2009 Beneficial effects of sorafenib on tumor progression, but not on radioiodine uptake, in patients with differentiated thyroid carcinoma. European Journal of Endocrinology 161 923-931. (https:// doi.org/10.1530/EJE-09-0702)

Hou P, Bojdani E \& Xing M 2010 Induction of thyroid gene expression and radioiodine uptake in thyroid cancer cells by targeting major signaling pathways. Journal of Clinical Endocrinology and Metabolism 95 820-828. (https://doi.org/10.1210/jc.2009-1888)

Huillard O, Tenenbaum F, Clerc J, Goldwasser F \& Groussin L 2015 Redifferentiation of iodine-refractory BRAF V600E-mutant metastatic papillary thyroid cancer with Dabrafenib-letter. Clinical Cancer Research 21 5639. (https://doi.org/10.1158/1078-0432.CCR-15-1648)

Huillard O, Tenenbaum F, Clerc J, Goldwasser F \& Groussin L 2017 Restoring radioiodine uptake in BRAF V600E-mutated papillary thyroid cancer. Journal of the Endocrine Society 1 285-287. (https:// doi.org/10.1210/js.2016-1114)

Iravani A, Solomon B, Pattison DA, Jackson P, Ravi Kumar AS, Kong G, Hofman MS, Akhurst T \& Hicks RJ 2019 Mitogen-activated protein kinase pathway inhibition for re-differentiation of radioiodinerefractory differentiated thyroid cancer: an evolving protocol. Thyroid 29 1634-1645. (https://doi.org/10.1089/thy.2019.0143)

Jaber T, Waguespack SG, Cabanillas ME, Elbanan M, Vu T, Dadu R, Sherman SI, Amit M, Santos EB, Zafereo M, et al. 2018 Targeted therapy in advanced thyroid cancer to resensitize tumors to radioactive iodine. Journal of Clinical Endocrinology and Metabolism 103 3698-3705. (https://doi.org/10.1210/jc.2018-00612)

Jang S, Yu XM, Odorico S, Clark M, Jaskula-Sztul R, Schienebeck CM, Kupcho KR, Harrison AD, Winston-Mcpherson GN, Tang W, et al. 2015 Novel analogs targeting histone deacetylase suppress aggressive thyroid cancer cell growth and induce re-differentiation. Cancer Gene Therapy 22 410-416. (https://doi.org/10.1038/cgt.2015.37)

Jeong H, Kim YR, Kim KN, Choe JG, Chung JK \& Kim MK 2006 Effect of all-trans retinoic acid on sodium/iodide symporter expression, radioiodine uptake and gene expression profiles in a human anaplastic thyroid carcinoma cell line. Nuclear Medicine and Biology 33 875-882. (https://doi.org/10.1016/j.nucmedbio.2006.07.004)

Kawaguchi A, Ikeda M, Endo T, Kogai T, Miyazaki A \& Onaya T 1997 Transforming growth factor-beta1 suppresses thyrotropin-induced $\mathrm{Na}+/ \mathrm{I}-$ symporter messenger RNA and protein levels in FRTL-5 rat thyroid cells. Thyroid 7 789-794. (https://doi.org/10.1089/ thy.1997.7.789)

Kebebew E, Peng M, Reiff E, Treseler P, Woeber KA, Clark OH, Greenspan FS, Lindsay S, Duh QY \& Morita E 2006 A phase II trial of rosiglitazone in patients with thyroglobulin-positive and radioiodine-negative differentiated thyroid cancer. Surgery $\mathbf{1 4 0}$ 960-966; discussion 966-967. (https://doi.org/10.1016/j. surg.2006.07.038)

Kebebew E, Lindsay S, Clark OH, Woeber KA, Hawkins R \& Greenspan FS 2009 Results of rosiglitazone therapy in patients with thyroglobulin-positive and radioiodine-negative advanced differentiated thyroid cancer. Thyroid 19 953-956. (https://doi. org/10.1089/thy.2008.0371)

Kelly WK, O'Connor OA, Krug LM, Chiao JH, Heaney M, Curley T, Macgregore-Cortelli B, Tong W, Secrist JP, Schwartz L, et al. 2005 Phase I study of an oral histone deacetylase inhibitor, suberoylanilide hydroxamic acid, in patients with advanced cancer. Journal of Clinical Oncology 23 3923-3931. (https://doi.org/10.1200/ JCO.2005.14.167)

Kim TH, Yoo YH, Kang DY, Suh H, Park MK, Park KJ \& Kim SH 2009 Efficacy on anaplastic thyroid carcinoma of valproic acid alone or in combination with doxorubicin, a synthetic chenodeoxycholic acid derivative, or lactacystin. International Journal of Oncology $\mathbf{3 4}$ 1353-1362. (https://doi.org/10.3892/ijo_00000262)

Kim J, Song J, Ji HD, Yoo EK, Lee JE, Lee SB, Oh JM, Lee S, Hwang JS, Yoon H, et al. 2019 Discovery of potent, selective, and orally bioavailable estrogen-related receptor-gamma inverse agonists to https://erc.bioscientifica.com

https://doi.org/10.1530/ERC-19-0491
(C) 2020 Society for Endocrinology Published by Bioscientifica Ltd. Printed in Great Britain 
restore the sodium iodide symporter function in anaplastic thyroid cancer. Journal of Medicinal Chemistry 62 1837-1858. (https://doi. org/10.1021/acs.jmedchem.8b01296)

Kitazono M, Robey R, Zhan Z, Sarlis NJ, Skarulis MC, Aikou T, Bates S \& Fojo T 2001 Low concentrations of the histone deacetylase inhibitor, depsipeptide (FR901228), increase expression of the $\mathrm{Na}(+) / \mathrm{I}(-)$ symporter and iodine accumulation in poorly differentiated thyroid carcinoma cells. Journal of Clinical Endocrinology and Metabolism $\mathbf{8 6}$ 3430-3435. (https://doi.org/10.1210/jcem.86.7.7621)

Kogai T, Sajid-Crockett S, Newmarch LS, Liu YY \& Brent GA 2008 Phosphoinositide-3-kinase inhibition induces sodium/iodide symporter expression in rat thyroid cells and human papillary thyroid cancer cells. Journal of Endocrinology 199 243-252. (https:// doi.org/10.1677/JOE-08-0333)

Kurebayashi J, Tanaka K, Otsuki T, Moriya T, Kunisue H, Uno M \& Sonoo H 2000 All-trans-retinoic acid modulates expression levels of thyroglobulin and cytokines in a new human poorly differentiated papillary thyroid carcinoma cell line, KTC-1. Journal of Clinical Endocrinology and Metabolism 85 2889-2896. (https://doi. org/10.1210/jcem.85.8.6732)

Lakshmanan A, Doseff AI, Ringel MD, Saji M, Rousset B, Zhang X \& Jhiang SM 2014 Apigenin in combination with Akt inhibition significantly enhances thyrotropin-stimulated radioiodide accumulation in thyroid cells. Thyroid 24 878-887. (https://doi. org/10.1089/thy.2013.0614)

Lakshmanan A, Scarberry D, Green JA, Zhang X, Selmi-Ruby S \& Jhiang SM 2015 Modulation of thyroidal radioiodide uptake by oncological pipeline inhibitors and apigenin. Oncotarget 6 31792-31804. (https://doi.org/10.18632/oncotarget.5172)

Lan L, Basourakos S, Cui D, Zuo X, Deng W, Huo L, Chen L, Zhang G, Deng L, Shi B, et al. 2017 Inhibiting beta-catenin expression promotes efficiency of radioiodine treatment in aggressive follicular thyroid cancer cells probably through mediating NIS localization. Oncology Reports 37 426-434. (https://doi.org/10.3892/or.2016.5228)

Landa I, Ibrahimpasic T, Boucai L, Sinha R, Knauf JA, Shah RH, Dogan S, Ricarte-Filho JC, Krishnamoorthy GP, Xu B, et al. 2016 Genomic and transcriptomic hallmarks of poorly differentiated and anaplastic thyroid cancers. Journal of Clinical Investigation 126 1052-1066. (https://doi.org/10.1172/JCI85271)

Landa I, Pozdeyev N, Korch C, Marlow LA, Smallridge RC, Copland JA, Henderson YC, Lai SY, Clayman GL, Onoda N, et al. 2019 Comprehensive genetic characterization of human thyroid cancer cell lines: a validated panel for preclinical studies. Clinical Cancer Research 25 3141-3151. (https://doi.org/10.1158/1078-0432.CCR-182953)

Lavarone E, Puppin C, Passon N, Filetti S, Russo D \& Damante G 2013 The PARP inhibitor PJ34 modifies proliferation, NIS expression and epigenetic marks in thyroid cancer cell lines. Molecular and Cellular Endocrinology 365 1-10. (https://doi.org/10.1016/j.mce.2012.08.019)

Leboulleux S, Dupuy C, Lacroix L, Attard M, Grimaldi S, Corre R, Ricard M, Nasr S, Berdelou A, Hadoux J, et al. 2019 Redifferentiation of a BRAF(K601E)-mutated poorly differentiated thyroid cancer patient with dabrafenib and trametinib treatment. Thyroid $\mathbf{2 9}$ 735-742. (https://doi.org/10.1089/thy.2018.0457)

Lee WW, Lee B, Kim SJ, Jin J, Moon DH \& Lee H 2003 Kinetics of iodide uptake and efflux in various human thyroid cancer cells by expressing sodium iodide symporter gene via a recombinant adenovirus. Oncology Reports 10 845-849. (https://doi.org/10.3892/ or.10.4.845)

Li L, Lv B, Chen B, Guan M, Sun Y, Li H, Zhang B, Ding C, He S \& Zeng Q 2015 Inhibition of miR-146b expression increases radioiodine-sensitivity in poorly differential thyroid carcinoma via positively regulating NIS expression. Biochemical and Biophysical Research Communications 462 314-321.

Lin JT, Wu MS, Wang WS, Yen CC, Chiou TJ, Liu JH, Yang MH, Chao TC, Chou SC \& Chen PM 2003 All-trans retinoid acid increases
Notch1 transcript expression in acute promyelocytic leukemia. Advances in Therapy 20 337-343. (https://doi.org/10.1007/ bf02849800)

Lin X, Fischer AH, Ryu KY, Cho JY, Sferra TJ, Kloos RT, Mazzaferri EL \& Jhiang SM 2004 Application of the Cre/loxP system to enhance thyroid-targeted expression of sodium/iodide symporter. Journal of Clinical Endocrinology and Metabolism 89 2344-2350. (https://doi. org/10.1210/jc.2003-031963)

Liu YY, Stokkel MP, Pereira AM, Corssmit EP, Morreau HA, Romijn JA \& Smit JW 2006a Bexarotene increases uptake of radioiodide in metastases of differentiated thyroid carcinoma. European Journal of Endocrinology 154 525-531. (https://doi.org/10.1530/eje.1.02123)

Liu YY, Van Der Pluijm G, Karperien M, Stokkel MP, Pereira AM, Morreau J, Kievit J, Romijn JA \& Smit JW 2006b Lithium as adjuvant to radioiodine therapy in differentiated thyroid carcinoma: clinical and in vitro studies. Clinical Endocrinology 64 617-624. (https://doi. org/10.1111/j.1365-2265.2006.02515.x)

Liu YY, Zhang X, Ringel MD \& Jhiang SM 2012 Modulation of sodium iodide symporter expression and function by LY294002, Akti-1/2 and rapamycin in thyroid cells. Endocrine-Related Cancer 19 291-304. (https://doi.org/10.1530/ERC-11-0288)

Liu L, Li D, Chen Z, Yang J, Ma Y, Cai H, Shan C, Lv Z \& Zhang X 2017 Wild-type P53 induces sodium/iodide symporter expression allowing radioiodide therapy in anaplastic thyroid cancer. Cellular Physiology and Biochemistry 43 905-914. (https://doi.org/10.1159/000481640)

Liu J, Liu R, Shen X, Zhu G, Li B \& Xing M 2019 The genetic duet of BRAF V600E and tert promoter mutations robustly predicts the loss of radioiodine avidity in recurrent papillary thyroid cancer. Journal of Nuclear Medicine 61 177-182.

Lopez-Campistrous A, Adewuyi EE, Benesch MGK, Ko YM, Lai R, Thiesen A, Dewald J, Wang P, Chu K, Ghosh S, et al. 2016 PDGFRalpha regulates follicular cell differentiation driving treatment resistance and disease recurrence in papillary thyroid cancer. EBiomedicine 12 86-97. (https://doi.org/10.1016/j.ebiom.2016.09.007)

Luster M, Aktolun C, Amendoeira I, Barczynski M, Bible KC, Duntas LH, Elisei R, Handkiewicz-Junak D, Hoffmann M, Jarzab B, et al. 2019 European perspective on 2015 American Thyroid Association management guidelines for adult patients with thyroid nodules and differentiated thyroid cancer: Proceedings of an Interactive International Symposium. Thyroid 29 7-26. (https://doi.org/10.1089/ thy.2017.0129)

Marsee DK, Venkateswaran A, Tao H, Vadysirisack D, Zhang Z, Vandre DD \& Jhiang SM 2004 Inhibition of heat shock protein 90, a novel RET/PTC1-associated protein, increases radioiodide accumulation in thyroid cells. Journal of Biological Chemistry 279 43990-43997. (https://doi.org/10.1074/jbc.M407503200)

Massimino M, Tirro E, Stella S, Frasca F, Vella V, Sciacca L, Pennisi MS, Vitale SR, Puma A, Romano C, et al. 2018 Effect of combined epigenetic treatments and ectopic NIS expression on undifferentiated thyroid cancer cells. Anticancer Research 38 6653-6662. (https://doi. org/10.21873/anticanres.13032)

Montero-Conde C, Ruiz-Llorente S, Dominguez JM, Knauf JA, Viale A, Sherman EJ, Ryder M, Ghossein RA, Rosen N \& Fagin JA 2013 Relief of feedback inhibition of HER3 transcription by RAF and MEK inhibitors attenuates their antitumor effects in BRAF-mutant thyroid carcinomas. Cancer Discovery 3 520-533. (https://doi. org/10.1158/2159-8290.CD-12-0531)

Mu D, Huang R, Li S, Ma X, Lou C \& Kuang A 2012 Combining transfer of TTF- 1 and Pax- 8 gene: a potential strategy to promote radioiodine therapy of thyroid carcinoma. Cancer Gene Therapy 19 402-411. (https://doi.org/10.1038/cgt.2012.13)

Nagarajah J, Le M, Knauf JA, Ferrandino G, Montero-Conde C, Pillarsetty N, Bolaender A, Irwin C, Krishnamoorthy GP, Saqcena M, et al. 2016 Sustained ERK inhibition maximizes responses of BrafV600E thyroid cancers to radioiodine. Journal of Clinical Investigation 126 4119-4124. (https://doi.org/10.1172/JCI89067) (c) 2020 Society for Endocrinology Published by Bioscientifica Ltd. Printed in Great Britain 
Nicolussi A, D’Inzeo S, Santulli M, Colletta G \& Coppa A 2003 TGF-beta control of rat thyroid follicular cells differentiation. Molecular and Cellular Endocrinology 207 1-11. (https://doi.org/10.1016/s03037207(03)00238-7)

Nilubol N, Merkel R, Yang L, Patel D, Reynolds JC, Sadowski SM, Neychev V \& Kebebew E 2017 A phase II trial of valproic acid in patients with advanced, radioiodine-resistant thyroid cancers of follicular cell origin. Clinical Endocrinology 86 128-133. (https://doi. org/10.1111/cen.13154)

Oh SW, Moon SH, Park DJ, Cho BY, Jung KC, Lee DS \& Chung JK 2011 Combined therapy with 131I and retinoic acid in Korean patients with radioiodine-refractory papillary thyroid cancer. European Journal of Nuclear Medicine and Molecular Imaging 38 1798-1805. (https://doi. org/10.1007/s00259-011-1849-2)

Oh JM, Kalimuthu S, Gangadaran P, Baek SH, Zhu L, Lee HW, Rajendran RL, Hong CM, Jeong SY, Lee SW, et al. 2018 Reverting iodine avidity of radioactive-iodine refractory thyroid cancer with a new tyrosine kinase inhibitor (K905-0266) excavated by highthroughput NIS (sodium iodide symporter) enhancer screening platform using dual reporter gene system. Oncotarget 9 7075-7087. (https://doi.org/10.18632/oncotarget.24159)

Pak K, Shin S, Kim SJ, Kim IJ, Chang S, Koo P, Kwak J \& Kim JH 2018 Response of retinoic acid in patients with radioactive iodinerefractory thyroid cancer: a meta-analysis. Oncology Research and Treatment 41 100-104. (https://doi.org/10.1159/000484206)

Park JW, Zarnegar R, Kanauchi H, Wong MG, Hyun WC, Ginzinger DG, Lobo M, Cotter P, Duh QY \& Clark OH 2005 Troglitazone, the peroxisome proliferator-activated receptor-gamma agonist, induces antiproliferation and redifferentiation in human thyroid cancer cell lines. Thyroid 15 222-231. (https://doi.org/10.1089/thy.2005.15.222)

Patel PN, Yu XM, Jaskula-Sztul R \& Chen H 2014 Hesperetin activates the Notch1 signaling cascade, causes apoptosis, and induces cellular differentiation in anaplastic thyroid cancer. Annals of Surgical Oncology 21 (Supplement 4) S497-S504. (https://doi.org/10.1245/ s10434-013-3459-7)

Philips JC, Petite C, Willi JP, Buchegger F \& Meier CA 2004 Effect of peroxisome proliferator-activated receptor gamma agonist, rosiglitazone, on dedifferentiated thyroid cancers. Nuclear Medicine Communications 25 1183-1186. (https://doi.org/10.1097/00006231-200412000-00005)

Plantinga TS, Heinhuis B, Gerrits D, Netea MG, Joosten LA, Hermus AR, Oyen WJ, Schweppe RE, Haugen BR, Boerman OC, et al. 2014 mTOR Inhibition promotes TTF1-dependent redifferentiation and restores iodine uptake in thyroid carcinoma cell lines. Journal of Clinical Endocrinology and Metabolism 99 E1368-E1375. (https://doi. org/10.1210/jc.2014-1171)

Plantinga TS, Tesselaar MH, Morreau H, Corssmit EP, Willemsen BK, Kusters B, Van Engen-Van Grunsven AC, Smit JW \& Netea-Maier RT 2016 Autophagy activity is associated with membranous sodium iodide symporter expression and clinical response to radioiodine therapy in non-medullary thyroid cancer. Autophagy 12 1195-1205. (https://doi.org/10.1080/15548627.2016.1174802)

Provenzano MJ, Fitzgerald MP, Krager K \& Domann FE 2007 Increased iodine uptake in thyroid carcinoma after treatment with sodium butyrate and decitabine (5-Aza-dC). Otolaryngology: Head and Neck Surgery 137 722-728. (https://doi.org/10.1016/j.otohns.2007.07.030)

Pugliese M, Fortunati N, Germano A, Asioli S, Marano F, Palestini N, Frairia R, Boccuzzi G \& Catalano MG 2013 Histone deacetylase inhibition affects sodium iodide symporter expression and induces 131I cytotoxicity in anaplastic thyroid cancer cells. Thyroid $\mathbf{2 3}$ 838-846. (https://doi.org/10.1089/thy.2012.0359)

Puppin C, D'Aurizio F, D'Elia AV, Cesaratto L, Tell G, Russo D, Filetti S, Ferretti E, Tosi E, Mattei T, et al. 2005 Effects of histone acetylation on sodium iodide symporter promoter and expression of thyroidspecific transcription factors. Endocrinology 146 3967-3974. (https:// doi.org/10.1210/en.2005-0128)
Puppin C, Passon N, Hershman JM, Filetti S, Bulotta S, Celano M, Russo D \& Damante G 2012 Cooperative effects of SAHA and VPA on NIS gene expression and proliferation of thyroid cancer cells. Journal of Molecular Endocrinology 48 217-227. (https://doi. org/10.1530/JME-11-0063)

Raman P \& Koenig RJ 2014 Pax-8-PPAR-gamma fusion protein in thyroid carcinoma. Nature Reviews: Endocrinology 10 616-623. (https://doi.org/10.1038/nrendo.2014.115)

Read ML, Lewy GD, Fong JC, Sharma N, Seed RI, Smith VE, Gentilin E, Warfield A, Eggo MC, Knauf JA, et al. 2011 Proto-oncogene PBF/ PTTG1IP regulates thyroid cell growth and represses radioiodide treatment. Cancer Research 71 6153-6164. (https://doi. org/10.1158/0008-5472.CAN-11-0720)

Riesco-Eizaguirre G, Gutierrez-Martinez P, Garcia-Cabezas MA, Nistal M \& Santisteban P 2006 The oncogene BRAF V600E is associated with a high risk of recurrence and less differentiated papillary thyroid carcinoma due to the impairment of Na+/I- targeting to the membrane. Endocrine-Related Cancer 13 257-269. (https://doi. org/10.1677/erc.1.01119)

Riesco-Eizaguirre G, De La Vieja A, Rodriguez I, Miranda S, MartinDuque P, Vassaux G \& Santisteban P 2011 Telomerase-driven expression of the sodium iodide symporter (NIS) for in vivo radioiodide treatment of cancer: a new broad-spectrum NIS-mediated antitumor approach. Journal of Clinical Endocrinology and Metabolism 96 E1435-E1443. (https://doi.org/10.1210/jc.2010-2373)

Riesco-Eizaguirre G, Wert-Lamas L, Perales-Paton J, Sastre-Perona A, Fernandez LP \& Santisteban P 2015 The miR-146b-3p/PAX8/NIS regulatory circuit modulates the differentiation phenotype and function of thyroid cells during carcinogenesis. Cancer Research $\mathbf{7 5}$ 4119-4130.

Rosenbaum-Krumme SJ, Freudenberg LS, Jentzen W, Bockisch A \& Nagarajah J 2012 Effects of rosiglitazone on radioiodine negative and progressive differentiated thyroid carcinoma as assessed by 124I PET/CT imaging. Clinical Nuclear Medicine 37 e47-e52. (https://doi. org/10.1097/RLU.0b013e3182443ca6)

Rothenberg SM, Daniels GH \& Wirth LJ 2015 Redifferentiation of iodine-refractory BRAF V600E-mutant metastatic papillary thyroid cancer with Dabrafenib-response. Clinical Cancer Research 21 5640-5641. (https://doi.org/10.1158/1078-0432.CCR-15-2298)

Ruan M, Liu M, Dong Q \& Chen L 2015 Iodide- and glucose-handling gene expression regulated by sorafenib or cabozantinib in papillary thyroid cancer. Journal of Clinical Endocrinology and Metabolism 100 1771-1779. (https://doi.org/10.1210/jc.2014-3023)

Russo D, Durante C, Bulotta S, Puppin C, Puxeddu E, Filetti S \& Damante G 2013 Targeting histone deacetylase in thyroid cancer. Expert Opinion on Therapeutic Targets 17 179-193. (https://doi.org/10. 1517/14728222.2013.740013)

Salem AK, Fenton MS, Marion KM \& Hershman JM 2008 Effect of sunitinib on growth and function of FRTL-5 thyroid cells. Thyroid $\mathbf{1 8}$ 631-635. (https://doi.org/10.1089/thy.2007.0336)

Schmohl KA, Dolp P, Schug C, Knoop K, Klutz K, Schwenk N, Bartenstein P, Nelson PJ, Ogris M, Wagner E, et al. 2017 Reintroducing the sodium-iodide symporter to anaplastic thyroid carcinoma. Thyroid 27 1534-1543. (https://doi.org/10.1089/ thy.2017.0290)

Schmutzler C \& Kohrle J 2000 Retinoic acid redifferentiation therapy for thyroid cancer. Thyroid 10 393-406. (https://doi.org/10.1089/ thy.2000.10.393)

Schmutzler C, Schmitt TL, Glaser F, Loos U \& Kohrle J 2002 The promoter of the human sodium/iodide-symporter gene responds to retinoic acid. Molecular and Cellular Endocrinology 189 145-155. (https://doi.org/10.1016/s0303-7207(01)00735-3)

Schreck R, Schnieders F, Schmutzler C \& Kohrle J 1994 Retinoids stimulate type I iodothyronine 5 '-deiodinase activity in human follicular thyroid carcinoma cell lines. Journal of Clinical (c) 2020 Society for Endocrinology Published by Bioscientifica Ltd. Printed in Great Britain 
Endocrinology and Metabolism 79 791-798. (https://doi.org/10.1210/ jcem.79.3.8077363)

Schweppe RE, Klopper JP, Korch C, Pugazhenthi U, Benezra M, Knauf JA, Fagin JA, Marlow LA, Copland JA, Smallridge RC, et al. 2008 Deoxyribonucleic acid profiling analysis of 40 human thyroid cancer cell lines reveals cross-contamination resulting in cell line redundancy and misidentification. Journal of Clinical Endocrinology and Metabolism 93 4331-4341. (https://doi.org/10.1210/jc.20081102)

Shen WT, Wong TS, Chung WY, Wong MG, Kebebew E, Duh QY \& Clark OH 2005 Valproic acid inhibits growth, induces apoptosis, and modulates apoptosis-regulatory and differentiation gene expression in human thyroid cancer cells. Surgery 138 979-984; discussion 984-985. (https://doi.org/10.1016/j.surg.2005.09.019)

Sherman EJ, Su YB, Lyall A, Schoder H, Fury MG, Ghossein RA, Haque S, Lisa D, Shaha AR, Tuttle RM, et al. 2013 Evaluation of Romidepsin for clinical activity and radioactive iodine reuptake in radioactive iodine-refractory thyroid carcinoma. Thyroid 23 593-599. (https:// doi.org/10.1089/thy.2012.0393)

Short SC, Suovuori A, Cook G, Vivian G \& Harmer C 2004 A phase II study using retinoids as redifferentiation agents to increase iodine uptake in metastatic thyroid cancer. Clinical Oncology 16 569-574. (https://doi.org/10.1016/j.clon.2004.06.018)

Simon D, Kohrle J, Schmutzler C, Mainz K, Reiners C \& Roher HD 1996 Redifferentiation therapy of differentiated thyroid carcinoma with retinoic acid: basics and first clinical results. Experimental and Clinical Endocrinology and Diabetes 104 (Supplement 4) 13-15. (https://doi. org/10.1055/s-0029-1211692)

Simon D, Korber C, Krausch M, Segering J, Groth P, Gorges R, Grunwald F, Muller-Gartner HW, Schmutzler C, Kohrle J, et al. 2002 Clinical impact of retinoids in redifferentiation therapy of advanced thyroid cancer: final results of a pilot study. European Journal of Nuclear Medicine and Molecular Imaging 29 775-782. (https://doi. org/10.1007/s00259-001-0737-6)

Singh TD, Jeong SY, Lee SW, Ha JH, Lee IK, Kim SH, Kim J, Cho SJ, Ahn BC, Lee J, et al. 2015 Inverse agonist of estrogen-related receptor gamma enhances sodium iodide symporter function through mitogen-activated protein kinase signaling in anaplastic thyroid cancer cells. Journal of Nuclear Medicine 56 1690-1696. (https://doi.org/10.2967/jnumed.115.160366)

Singh TD, Song J, Kim J, Chin J, Ji HD, Lee JE, Lee SB, Yoon H, Yu JH, Kim SK, et al. 2019 A novel orally active inverse agonist of estrogenrelated receptor gamma (ERRgamma), DN200434, a booster of NIS in anaplastic thyroid cancer. Clinical Cancer Research 25 5069-5081. (https://doi.org/10.1158/1078-0432.CCR-18-3007)

Smit JW, Shroder-Van Der Elst JP, Karperien M, Que I, Van Der Pluijm G, Goslings B, Romijn JA \& Van Der Heide D 2000 Reestablishment of in vitro and in vivo iodide uptake by transfection of the human sodium iodide symporter (hNIS) in a hNIS defective human thyroid carcinoma cell line. Thyroid 10 939-943. (https://doi.org/10.1089/ thy.2000.10.939)

Smit JW, Schroder-Van Der Elst JP, Karperien M, Que I, Stokkel M, Van Der Heide D \& Romijn JA 2002 Iodide kinetics and experimental (131)I therapy in a xenotransplanted human sodium-iodide symporter-transfected human follicular thyroid carcinoma cell line. Journal of Clinical Endocrinology and Metabolism 87 1247-1253. (https://doi.org/10.1210/jcem.87.3.8307)

Smith JA, Fan CY, Zou C, Bodenner D \& Kokoska MS 2007 Methylation status of genes in papillary thyroid carcinoma. Archives of Otolaryngology: Head and Neck Surgery 133 1006-1011. (https://doi. org/10.1001/archotol.133.10.1006)

Smith VE, Read ML, Turnell AS, Watkins RJ, Watkinson JC, Lewy GD, Fong JC, James SR, Eggo MC, Boelaert K, et al. 2009 A novel mechanism of sodium iodide symporter repression in differentiated thyroid cancer. Journal of Cell Science 122 3393-3402. (https://doi. org $/ 10.1242 /$ jcs.045427)
Smith VE, Franklyn JA \& Mccabe CJ 2011 Expression and function of the novel proto-oncogene PBF in thyroid cancer: a new target for augmenting radioiodine uptake. Journal of Endocrinology $\mathbf{2 1 0}$ 157-163. (https://doi.org/10.1530/JOE-11-0064)

Smith VE, Sharma N, Watkins RJ, Read ML, Ryan GA, Kwan PP, Martin A, Watkinson JC, Boelaert K, Franklyn JA, et al. 2013 Manipulation of PBF/PTTG1IP phosphorylation status; a potential new therapeutic strategy for improving radioiodine uptake in thyroid and other tumors. Journal of Clinical Endocrinology and Metabolism 98 2876-2886. (https://doi.org/10.1210/jc.2012-3640)

Somnay YR, Yu XM, Lloyd RV, Leverson G, Aburjania Z, Jang S, JaskulaSztul R \& Chen H 2017 Notch3 expression correlates with thyroid cancer differentiation, induces apoptosis, and predicts disease prognosis. Cancer 123 769-782. (https://doi.org/10.1002/cncr.30403)

Song J, Qiu W, Deng X, Qiu Z, Fan Y \& Yang Z 2018 A somatic mutation of RasGRP3 decreases $\mathrm{Na}(+) / \mathrm{I}(-)$ symporter expression in metastases of radioactive iodine-refractory thyroid cancer by stimulating the Akt signaling pathway. American Journal of Cancer Research 8 1847-1855.

Spitzweg C 2009 Gene therapy in thyroid cancer. Hormone and Metabolic Research 41 500-509. (https://doi.org/10.1055/s-0029-1220744)

Stephen JK, Chitale D, Narra V, Chen KM, Sawhney R \& Worsham MJ 2011 DNA methylation in thyroid tumorigenesis. Cancers 3 1732-1743. (https://doi.org/10.3390/cancers3021732)

Tavares C, Coelho MJ, Eloy C, Melo M, Da Rocha AG, Pestana A, Batista R, Ferreira LB, Rios E, Selmi-Ruby S, et al. 2018 NIS expression in thyroid tumors, relation with prognosis clinicopathological and molecular features. Endocrine Connections 7 78-90. (https://doi. org/10.1530/EC-17-0302)

Tepmongkol S, Keelawat S, Honsawek S \& Ruangvejvorachai P 2008 Rosiglitazone effect on radioiodine uptake in thyroid carcinoma patients with high thyroglobulin but negative total body scan: a correlation with the expression of peroxisome proliferator-activated receptor-gamma. Thyroid 18 697-704. (https://doi.org/10.1089/ thy.2008.0056)

Tesselaar MH, Crezee T, Swarts HG, Gerrits D, Boerman OC, Koenderink JB, Stunnenberg HG, Netea MG, Smit JW, NeteaMaier RT, et al. 2017 Digitalis-like compounds facilitate nonmedullary thyroid cancer redifferentiation through intracellular Ca2+, FOS, and autophagy-dependent pathways. Molecular Cancer Therapeutics 16 169-181. (https://doi.org/10.1158/1535-7163.MCT16-0460)

Tesselaar MH, Crezee T, Schuurmans I, Gerrits D, Nagarajah J, Boerman OC, Van Engen-Van Grunsven I, Smit JWA, Netea-Maier RT \& Plantinga TS 2018 Digitalislike compounds restore hNIS expression and iodide uptake capacity in anaplastic thyroid cancer. Journal of Nuclear Medicine 59 780-786. (https://doi.org/10.2967/ jnumed.117.200675)

Thompson RJ, Fletcher A, Brookes K, Nieto H, Alshahrani MM, Mueller JW, Fine NHF, Hodson DJ, Boelaert K, Read ML, et al. 2019 Dimerization of the sodium/iodide symporter. Thyroid 29 1485-1498. (https://doi.org/10.1089/thy.2019.0034)

Tuncel M, Aydin D, Yaman E, Tazebay UH, Guc D, Dogan AL, Tasbasan B \& Ugur O 2007 The comparative effects of gene modulators on thyroid-specific genes and radioiodine uptake. Cancer Biotherapy and Radiopharmaceuticals 22 281-288. (https://doi. org/10.1089/cbr.2006.319)

Vadysirisack DD, Venkateswaran A, Zhang Z \& Jhiang SM 2007 MEK signaling modulates sodium iodide symporter at multiple levels and in a paradoxical manner. Endocrine-Related Cancer 14 421-432. (https://doi.org/10.1677/erc.1.01263)

Van Herle AJ, Agatep ML, Padua 3rd DN, Totanes TL, Canlapan DV, Van Herle HM \& Juillard GJ 1990 Effects of 13 cis-retinoic acid on growth and differentiation of human follicular carcinoma cells (UCLA R0 $82 \mathrm{~W}-1$ ) in vitro. Journal of Clinical Endocrinology and Metabolism 71 755-763. (https://doi.org/10.1210/jcem-71-3-755) 
Vella V, Nicolosi ML, Cantafio P, Massimino M, Lappano R, Vigneri P, Ciuni R, Gangemi P, Morrione A, Malaguarnera R, et al. 2019 DDR1 regulates thyroid cancer cell differentiation via IGF-2/IR-A autocrine signaling loop. Endocrine-Related Cancer 26 197-214. (https://doi. org/10.1530/ERC-18-0310)

Venkataraman GM, Yatin M, Marcinek R \& Ain KB 1999 Restoration of iodide uptake in dedifferentiated thyroid carcinoma: relationship to human Na+/I-symporter gene methylation status. Journal of Clinical Endocrinology and Metabolism 84 2449-2457. (https://doi. org/10.1210/jcem.84.7.5815)

Wachter S, Damanakis AI, Elxnat M, Roth S, Wunderlich A, Verburg FA, Fellinger SA, Bartsch DK \& Di Fazio P 2018a Epigenetic modifications in thyroid cancer cells restore NIS and radio-iodine uptake and promote cell death. Journal of Clinical Medicine 7 E61. (https://doi.org/10.3390/jcm7040061)

Wachter S, Wunderlich A, Greene BH, Roth S, Elxnat M, Fellinger SA, Verburg FA, Luster M, Bartsch DK \& Di Fazio P 2018b Selumetinib activity in thyroid cancer cells: modulation of sodium iodide symporter and associated miRNAs. International Journal of Molecular Sciences 19 E2077. (https://doi.org/10.3390/ijms19072077)

Wachter S, Wunderlich A, Roth S, Mintziras I, Maurer E, Hoffmann S, Verburg FA, Fellinger SA, Holzer K, Bartsch DK, et al. 2018 c Individualised multimodal treatment strategies for anaplastic and poorly differentiated thyroid cancer. Journal of Clinical Medicine $\mathbf{7}$ E115. (https://doi.org/10.3390/jcm7050115)

Wassermann J, Bernier MO, Spano JP, Lepoutre-Lussey C, Buffet C, Simon JM, Menegaux F, Tissier F, Leban M \& Leenhardt L 2016 Outcomes and prognostic factors in radioiodine refractory differentiated thyroid carcinomas. Oncologist 21 50-58. (https://doi. org/10.1634/theoncologist.2015-0107)

Weyemi U, Caillou B, Talbot M, Ameziane-El-Hassani R, Lacroix L, Lagent-Chevallier O, Al Ghuzlan A, Roos D, Bidart JM, Virion A, et al. 2010 Intracellular expression of reactive oxygen speciesgenerating NADPH oxidase NOX4 in normal and cancer thyroid tissues. Endocrine-Related Cancer 17 27-37. (https://doi.org/10.1677/ ERC-09-0175)

Xiao X, Ning L \& Chen H 2009 Notch1 mediates growth suppression of papillary and follicular thyroid cancer cells by histone deacetylase inhibitors. Molecular Cancer Therapeutics 8 350-356. (https://doi. org/10.1158/1535-7163.MCT-08-0585)

Xing M, Usadel H, Cohen Y, Tokumaru Y, Guo Z, Westra WB, Tong BC, Tallini G, Udelsman R, Califano JA, et al. 2003 Methylation of the thyroid-stimulating hormone receptor gene in epithelial thyroid tumors: a marker of malignancy and a cause of gene silencing. Cancer Research 63 2316-2321.

Xu J \& Hershman JM 2006 Histone deacetylase inhibitor depsipeptide represses nicotinamide $\mathrm{N}$-methyltransferase and hepatocyte nuclear factor-1beta gene expression in human papillary thyroid cancer cells. Thyroid 16 151-160. (https://doi.org/10.1089/thy.2006.16.151)

Yang X, Li J, Li X, Liang Z, Gao W, Liang J, Cheng S \& Lin Y 2017 Tert promoter mutation predicts radioiodine-refractory character in distant metastatic differentiated thyroid cancer. Journal of Nuclear Medicine 58 258-265. (https://doi.org/10.2967/jnumed.116.180240)

Yu XM, Jaskula-Sztul R, Ahmed K, Harrison AD, Kunnimalaiyaan M \& Chen H 2013 Resveratrol induces differentiation markers expression in anaplastic thyroid carcinoma via activation of Notch1 signaling and suppresses cell growth. Molecular Cancer Therapeutics 12 1276-1287. (https://doi.org/10.1158/1535-7163.MCT-12-0841)

Zarnegar R, Brunaud L, Kanauchi H, Wong M, Fung M, Ginzinger D, Duh QY \& Clark OH 2002 Increasing the effectiveness of radioactive iodine therapy in the treatment of thyroid cancer using trichostatin A, a histone deacetylase inhibitor. Surgery 132 984-990; discussion 990. (https://doi.org/10.1067/msy.2002.128690)

Zhang H \& Chen D 2018 Synergistic inhibition of MEK/ERK and BRAF V600E with PD98059 and PLX4032 induces sodium/iodide symporter (NIS) expression and radioiodine uptake in BRAF mutated papillary thyroid cancer cells. Thyroid Research 11 13. (https://doi. org/10.1186/s13044-018-0057-6)

Zhang Y, Jia S, Liu Y, Li B, Wang Z, Lu H \& Zhu C 2007 A clinical study of all-trans-retinoid-induced differentiation therapy of advanced thyroid cancer. Nuclear Medicine Communications 28 251-255. (https://doi.org/10.1097/MNM.0b013e3280708ebf)

Zhang Z, Liu D, Murugan AK, Liu Z \& Xing M 2014 Histone deacetylation of NIS promoter underlies BRAF V600E-promoted NIS silencing in thyroid cancer. Endocrine-Related Cancer 21 161-173. (https://doi.org/10.1530/ERC-13-0399)

Received in final form 25 February 2020

Accepted 19 March 2020

Accepted Manuscript published online 19 March 2020 (c) 2020 Society for Endocrinology Published by Bioscientifica Ltd. Printed in Great Britain 